\title{
Differences in Metabolic and Physiological Responses between Local and Widespread Grapevine Cultivars under Water Deficit Stress
}

\author{
Igor Florez-Sarasa ${ }^{1, *,+} \mathbb{C}$, María José Clemente-Moreno ${ }^{2, *,+}{ }^{+}$, Josep Cifre ${ }^{2}$, Miquel Capó ${ }^{2}$, \\ Miquel Llompart ${ }^{2}$, Alisdair R. Fernie ${ }^{3}$ and Josefina Bota ${ }^{2}$ \\ 1 Centre for Research in Agricultural Genomics (CRAG) CSIC-IRTA-UAB-UB, Campus UAB Bellaterra, \\ 08193 Barcelona, Spain \\ 2 Research Group on Plant Biology, Balearic Islands University, Ctra Valldemossa km 7.5, \\ 07122 Palma de Mallorca, Spain; pep.cifre@uib.es (J.C.); miquel.capo@uib.es (M.C.); \\ miqllc@gmail.com (M.L.); j.bota@uib.es (J.B.) \\ 3 Max-Planck-Institute of Molecular Plant Physiology, Am Mühlenberg 1, 14476 Potsdam-Golm, Germany; \\ Fernie@mpimp-golm.mpg.de \\ * Correspondence: igor.florez@cragenomica.es (I.F.-S.); esojariam2@gmail.com (M.J.C.-M.); \\ Tel.: +34-935-636-600 (I.F.-S.); +34-971-17-34-48 (M.J.C.-M.) \\ + These authors contributed equally to the manuscript.
}

Received: 10 July 2020; Accepted: 17 July 2020; Published: 21 July 2020

\begin{abstract}
Climate change forecasts suggest temperature increases and lower rainfall rates, both of which challenge viticulture, particularly in semi-arid areas where water availability is critical. In this scenario, the use of the genetic variability in grapevine varieties reported around the world represents an important strategy for the selection of climate-resilient cultivars. In this work, physiological and metabolomics analyses were conducted to compare the water deficit stress (WDS) responses of red and white, local and widespread grapevines cultivars. Leaf gas exchange, water use efficiency (WUE) and water relation parameters were determined in plants under well-watered and WDS conditions alongside assessment of the levels of foliar primary metabolites using gas-chromatography coupled to mass-spectrometry. Results denote that red and white local cultivars displayed more adapted physiological performance under WDS as compared to the widely-distributed ones. Multivariate analyses and specific changes in leaf primary metabolites indicate genotype-specific responses of local cultivars as compared to widespread ones. Differences in ascorbate-related and shikimate/phenylpropanoid metabolism could explain the better physiological performance under WDS in red local as compared to widespread cultivars. On the other hand, coordinated changes in respiratory- and stress-related sugars and amino acids could underlie the better WUE under WDS in the white local cultivar. All these results suggest several metabolic targets that could be useful as metabolic markers or for metabolic engineering in grapevine breeding programs to improve drought tolerance.
\end{abstract}

Keywords: water deficit stress; Vitis vinifera; genetic variability; local cultivars; metabolomics; water use efficiency

\section{Introduction}

Water availability is one of the main limiting factors affecting crop production in arid and semi-arid regions. This situation has further worsened in recent years due to climate change, which represents a major threat to the future of our primary agricultural productivity [1]. In this context, a broad effort is needed to reduce the impacts of global change and optimize the use of irrigation, which is increasingly 
necessary in Mediterranean viticulture. Over decades, the responses of grapevine to environmental changes have been under continuous review, with special attention to those expected under water deficit [2-5]. The selection of more water-use efficient or more drought-tolerant genotypes has been proposed as an important strategy to overcome global change impacts [6-9]. Generally, grapevine is considered as a drought-tolerant species, however, physiological responses to environmental constraints including stomatal regulation, photosynthetic capacity and water use efficiency (WUE) vary among genotypes [10]. While there is a wide knowledge concerning the intra-specific variability in the physiological response to water deficit stress (WDS) and WUE [10-21], the underlying mechanisms associated with this variability are not fully understood. The binary classification isohydric/anisohydric was widely used to identify genotype behaviors based on differences in stomatal conductance patterns in response to water potentials [12,20]. However, recent studies suggest that these two strategies can occur within the same variety depending on the experimental conditions (e.g., climatic conditions, growing season, water treatment, field or controlled conditions) so, even if a continuum between isohydric to anisohydric behavior exists, different strategies in response to drought have been identified and its implications in WUE deserve to be further studied [10,22-25]. In this sense, local grapevine varieties from the Balearic Islands have been described as physiologically better adapted to deficient irrigation, particularly with regard to WUE $[10,13]$. These local cultivars are documented as ancient pre-phylloxera vines cultivated in the Balearic Islands [26] and have been widely and thoroughly studied at the level of genetic characterization, population structure and pedigree $[27,28]$. However, a better understanding of the genotype-specific molecular responses to WDS and their link to physiological responses is still necessary in order to achieve a more efficient viticulture in the future.

Better performance under drought and higher temperatures involves specific morpho-anatomical, physiological and metabolic adaptations [20,29]. Metabolite profiling approaches have been successfully employed to study environmental responses in wild, model and crop plants (reviewed in Obata and Fernie, Peters et al. and Alseekh et al. [30-32]). More recently, the combination of ecophysiological and metabolomics approaches has improved our current understanding of plant responses to environmental clues [33-35]. In the particular case of grapevine and other Mediterranean woody crops, the use of metabolomics together with transcriptomics and proteomics approaches has been recently proposed as key for advancing in the characterization of plant genotypes exhibiting physiological and/or genetic traits conferring abiotic stress tolerance [36]. While different studies have investigated the genotypic variability of grapevine metabolic responses to WDS, most of them have focused on berry development and quality composition [37-41]. However, the regulation of grapevine leaf metabolism under WDS is key for understanding berry development, since the berry is a sink tissue tightly depending on leaf metabolism [42]. This issue can be relevant for breeding programs, especially when considering the different physiological behavior of varieties from arid and semi-arid areas that could diminish the effect of water deficit and support productivity [4,42]. That said, while some studies have compared grapevine genotypic differences on leaf metabolic responses to drought [42-44], the number of genotypes used has been limited (i.e., no more than two) and, to our knowledge, none of them included red and white cultivars locally adapted to the Mediterranean climate.

In this work, we have studied grapevine WDS responses in local and widely-distributed cultivar (four red and two white) at the leaf level by measuring several ecophysiological parameters in combination with metabolite profiling analysis. Given evidence of a higher WUE in local cultivars from the Balearic Islands, as introduced above, we hypothesize that local cultivars should display metabolic adaptations related to their better responses to WDS. Common physiological and metabolic responses to WDS were observed in all genotypes. Nevertheless, multivariate analyses of metabolite data separated locally from widely-distributed cultivars and some metabolites displayed specific patterns in these cultivars. The associations between specific metabolic features of local cultivars and their physiological differences to widespread cultivars are discussed. 


\section{Materials and Methods}

\subsection{Plant Material and Treatments}

Six grapevine cultivars were chosen to perform the present study; two red and one white local cultivar(s): Escursac, Callet and Giró Ros; and two red and one white widespread ones: Merlot, Syrah and Moscatel. The experiment was performed in summer 2016 (from 4th July to 22th July) at the experimental field site of Universitat de les Illes Balears $\left(39^{\circ} 35^{\prime} \mathrm{N}, 2^{\circ} 39^{\prime} \mathrm{E}\right)$ (Balearic Islands, Spain). Eight plants per cultivar were maintained without fruits (manually cut) since grape development and ripening induces large changes in the metabolic activity of plants acting as the most active sink for photosynthates [42,45]. Therefore, plants were grown without fruits avoiding the effect of other major factors, such as differences among cultivars in sink source ratios. Also, non-grafted plants were used in order to avoid confounding effects of rootstock scion interactions. All plants were obtained by direct rooting from $0.3 \mathrm{~m}$ dormant cuttings with at least 3 leaf nodes. Cuttings were soaked in $0.3 \%$ Captan solution for $3 \mathrm{~h}$ and hydrated for $24 \mathrm{~h}$. After that, rooting was induced by indole-3-butyric acid (IBA) $2 \mathrm{~g} \mathrm{~L}^{-1}$, and plants were maintained in a greenhouse under controlled conditions. Soil temperature at $2 \mathrm{~cm}$ deep was $26-28{ }^{\circ} \mathrm{C}$. Air temperature was $23{ }^{\circ} \mathrm{C}$ and air humidity about $80 \%$. When cuttings presented 4-5 expanded leaves, they were transplanted into pots and grown outdoors in $15 \mathrm{~L}$ pots filled with organic substrate and perlite mixture (3:1) and placed in a completely randomized design. They were irrigated daily from May until the start of the experiment and supplemented every 3-5 days with organic-mineral fertilizer NPK containing (\%): N, 5; $\mathrm{P}_{2} \mathrm{O}_{5}, 8 ; \mathrm{K}_{2} \mathrm{O} 15 ; \mathrm{MgO}$, 2; organic C, 17.4, humic acid, $5 ; \mathrm{SO}_{3}, 15 ; \mathrm{Fe}, 1 ; \mathrm{Zn} 2 \times 10^{-3} ; \mathrm{Mn} 1 \times 10^{-2}$. To avoid soil evaporation during the experiment a blanket of acrylic fibers of $7 \mathrm{~cm}$ thickness was placed in each pot and was only removed during water supply.

Two irrigation regimes were established on the basis of stomatal conductance $\left(\mathrm{g}_{\mathrm{s}}\right)$ measurements: field capacity or well-watered $\left(g_{s}>200 \mathrm{mmol} \mathrm{H}_{2} \mathrm{O} \mathrm{m} \mathrm{m}^{-2} \mathrm{~s}^{-1}\right)$ and moderate water stress $\left(50<\mathrm{g}_{\mathrm{s}}<150 \mathrm{mmol} \mathrm{H}_{2} \mathrm{O} \mathrm{m}^{-2} \mathrm{~s}^{-1}\right.$ ) [46]. Well-watered (WW) plants were maintained at field capacity throughout the experiment. For water deficit stressed (WDS) plants, the irrigation was stopped and $g_{s}$ was monitored every day until the required level of stress was achieved (typically 4-5 days after withholding water). Once moderate stress values were achieved, pots were weighted daily in the evening and the amount of water consumed was replenished to maintain the same level of drought. The physiological and metabolic determinations were performed two weeks after achieving the moderate water stress level.

\subsection{Soil Water Content and Climatic Conditions}

To calculate the soil water content (SWC), an aliquot of $250 \mathrm{~cm}^{3}(5 \mathrm{~cm}$ approx. below the surface) for each pot was obtained every two days during the water deficit stress period. The aliquots were weighed and dried in the oven at $65^{\circ} \mathrm{C}$ for one week. Then, soil water content was calculated as follows:

$$
\text { SWC }(\%)=\left[\text { volume of water }\left(\mathrm{cm}^{3}\right) / \text { volume of soil }\left(\mathrm{cm}^{3}\right)\right] \times 100
$$

The climatic conditions were the typical Mediterranean summer conditions. During the study, total precipitation was null, daily maximum, minimum and average temperature were $31.3 \pm 0.4{ }^{\circ} \mathrm{C}, 19.4 \pm 0.3{ }^{\circ} \mathrm{C}$, $25.7 \pm 0.3^{\circ} \mathrm{C}$ respectively and reference evapotranspiration (ETo) was $133 \mathrm{~mm}$ for all the period. Climatic data was obtained using a weather station 7450 Groweather (DAVIS instruments Corp, Hayward, California, USA), located at the experimental field at the Universitat de les Illes Balears (Mallorca, Spain).

\subsection{Plant Water Relations and Leaf Mass Area}

In order to determine the plant water status, leaf water potential at predawn $\left(\Psi_{\mathrm{PD}}\right)$ and midday $\left(\Psi_{\mathrm{MD}}\right)$ were measured in fully expanded leaves with a Scholander pressure chamber (Soilmoisture Equipment Corp., Santa Barbara, CA, USA). Three to six replicates per variety and treatment were taken from different plants. 
Leaf relative water content (RWC) was calculated based on fresh (FW), turgid (TW) and dry weight (DW) from each treatment and cultivar using leaf discs of $5.3 \mathrm{~cm}^{2}$ and applying the equation:

$$
\text { RWC }(\%)=(F W-D W) /(T W-D W) \times 100
$$

Whole plant hydraulic conductance ( $\mathrm{K}_{\text {plant }}$ specific to leaf area) was calculated based on the Ohm's law as described in El Aou-ouad et al. [47].

In addition, the leaf mass area $\left(\mathrm{LMA}=\right.$ dry weight $(\mathrm{DW}) / \mathrm{leaf}$ area $\left(\mathrm{g} / \mathrm{m}^{2}\right)$ was calculated using leaf discs of $5.3 \mathrm{~cm}^{2}$ according to Groom and Lamont [48].

\subsection{Gas Exchange Measurements}

Leaf net photosynthesis $\left(\mathrm{A}_{\mathrm{N}}\right)$, stomatal conductance $\left(\mathrm{g}_{\mathrm{s}}\right)$, internal $\mathrm{CO}_{2}$ concentration $\left(\mathrm{C}_{\mathrm{i}}\right)$ and transpiration rate (E) were measured up to six leaves per cultivar in the same days of plant water status measurements. Measurements were performed between 10:00 h and 12:00 h (local time) using an infrared open gas exchange system (Li-6400, Li-cor Inc., Lincoln, NE, USA) equipped with a $2 \mathrm{~cm}^{2}$ chamber. All measurements were performed under saturating light $\left(1500 \mu \mathrm{mol} \mathrm{m}{ }^{-2} \mathrm{~s}^{-1}\right)$ and a $\mathrm{CO}_{2}$ concentration of $400 \mu \mathrm{mol} \mathrm{CO}_{2} \mathrm{~mol}^{-1}$ air. Intrinsic water use efficiency $\left(\mathrm{WUE}_{\mathrm{i}}\right)$ was calculated as the ratio between $A_{N}$ and $g_{s}$.

\subsection{Leaf Carbon Isotope Composition $\left(\delta^{13} \mathrm{C}\right)$}

Between three and six samples from young leaves were taken for each cultivar and treatment at sampling time. Samples were dried for $48 \mathrm{~h}$ in an oven at $60{ }^{\circ} \mathrm{C}$ and ground into powder. Subsamples of $2 \mathrm{mg}$ were analyzed for isotope ratio $\left(\delta^{13} \mathrm{C}\right)$. Samples were combusted in an elemental analyzer (Thermo Flash EA 1112 Series, Bremen, Germany); $\mathrm{CO}_{2}$ was separated by chromatography and directly injected into a continuous-flow isotope ratio mass spectrometer (Thermo Finnigan Delta Plus, Bremen, Germany). Peach leaf standards (NIST 1547) were run every eight samples. $\delta^{13} \mathrm{C}$ was calculated as: $\delta^{13} \mathrm{C}$ sample $(\% \mathrm{o})=((\mathrm{R}$ sample $/ \mathrm{R}$ standard $)-1) \times 1000[49]$.

\subsection{Metabolite Profiling}

Metabolite analysis was performed in the same leaves used for gas exchange measurements. Leaves were sampled at midday and immediately frozen in liquid nitrogen for subsequent analysis. Leaf powder (approx. $50 \mathrm{mg}$ ) obtained by quick grinding under liquid nitrogen was extracted, derivatized and subsequently analyzed by gas chromatography-time of flight-mass spectrometry (GC-TOF-MS) as previously described [50]. The GC-TOF-MS system was composed of a CTC CombiPAL autosampler, an Agilent $6890 \mathrm{~N}$ gas chromatograph and a LECO Pegasus III time-of-flight mass spectrometer running in Electron Ionization (EI)+ mode. Metabolites were manually annotated by comparison with database entries of standards with the aid of TagFinder software [51]. Metabolite data is reported following recommended standards [52] with the parameters used for peak annotation being provided in Table S1. We collected three to six replicates per treatment and cultivar.

\subsection{Data and Statistical Analysis}

A univariate Analysis of Variance (ANOVA) was performed to study the influence of the cultivar, water treatment and their interaction on each physiological parameter or metabolite studied. The $p$-values of each factor (cultivar, water treatment and interaction) for all parameters studied can be found in Table S2. A Duncan test was used to test the significance of the differences between treatments and varieties $(p<0.05)$ in Table 1 and Table S3. The dendrogram showing the distances and the grouping among the different varieties and treatments was obtained from a multivariate Cluster Analysis using the mean data by variety and treatment from metabolite analysis. No data transformation was performed for that analysis and the distance between individuals was calculated as the square euclidean distance (extraction method). A Principal Component Analysis (PCA) was 
also performed using the mean data from metabolite analysis in order to plot the varieties and the treatments on the new principal component axis. The correlation coefficient between the original variables (metabolite analysis) and the new ones (principal components) was also obtained and can be found in Table S4. All the above mentioned analyses were computed using SPSS statistical software package version 25 (IBM Corp, 2016, Armonk, New York, NY, USA).

To process the GC-TOF-MS results, the intensity of a selected unique ion shown in Table S1 was normalized to that of ribitol which was added to each sample as an internal standard, as well as to the fresh weight of the materials used for metabolite extraction. Thereafter, fresh weight was corrected by the dry weight/fresh weight ratios (same as used for the RWC calculation) of the corresponding leaf sample. The value for each metabolite was divided by the mean of all the WW samples from all cultivars (i.e., the mean of WW samples from all cultivars was set to 1). This normalization allowed the comparison of the relative metabolite levels among cultivars and water treatments; letters denoting the significant differences between all the cultivars and treatments after ANOVA analysis are shown in Table S3.

In addition to the ANOVA analyses, Student's $t$-test comparisons were performed for each cultivar to analyze the response of the metabolites and physiological parameters to WDS in each cultivar individually. In this respect, fold-changes were calculated as the ratios WDS/WW, log2 transformed and the values were represented in the Heatmap of Figure 1, where asterisks denote significant $(p<0.05)$ differences between WW and WDS. The Heatmap was generated with the software MultiExperimentViewer-version 4.9.0 (http://mev.tm4.org) [53].

Pearson correlations presented in Tables S5 and S6 were performed between metabolite levels and physiological parameters under WDS treatment. Pearson coefficients were obtained with Microsoft EXCEL Software 2013 and $p$-values were calculated as previously described [54]. Pearson correlations were performed with individual replicates of physiological parameters and metabolite levels from red $(n=14)$ and white $(n=6)$ cultivars separately. In addition, we aimed to perform an explorative analysis of the multiple comparisons by Benjamini-Hochberg false discovery rate (FDR) correction as previously described [54]. Finally, the whole data set with all individual replicates used for all the above-mentioned analysis is provided in Table S7. 
Table 1. Physiological and anatomical parameters in all grapevine cultivars under well-watered (WW) and water deficit stress (WDS). Data is presented as means \pm SE for three to six replicates. Different letters denote significant $(p<0.05)$ differences between treatments and cultivars by Duncan test.

\begin{tabular}{|c|c|c|c|c|c|c|c|}
\hline & & Callet & Escursac & Merlot & Syrah & Giro Ros & Moscatel \\
\hline \multirow[t]{2}{*}{$\mathbf{A}_{\mathbf{N}}$} & WW & $17.68 \pm 0.86 \mathrm{de}$ & $17.55 \pm 0.61 \mathrm{de}$ & $15.47 \pm 1.01 \mathrm{~d}$ & $18.28 \pm 0.62 \mathrm{e}$ & $17.12 \pm 0.62 \mathrm{de}$ & $16.9 \pm 0.84 \mathrm{de}$ \\
\hline & WDS & $9.08 \pm 2.03 c$ & $7.85 \pm 0.46 b c$ & $5.14 \pm 0.36 a$ & $6.63 \pm 0.68 \mathrm{abc}$ & $6.34 \pm 0.09 \mathrm{ab}$ & $6.49 \pm 0.59 \mathrm{abc}$ \\
\hline \multirow[t]{2}{*}{$\mathrm{g}_{\mathrm{s}}$} & WW & $0.32 \pm 0.03 c$ & $0.29 \pm 0.02 b$ & $0.22 \pm 0.02 b$ & $0.32 \pm 0.02 c$ & $0.26 \pm 0.02 b c$ & $0.28 \pm 0.02 b c$ \\
\hline & WDS & $0.1 \pm 0.02 \mathrm{a}$ & $0.12 \pm 0.02 \mathrm{a}$ & $0.06 \pm 0 \mathrm{a}$ & $0.09 \pm 0.02 a$ & $0.06 \pm 0 \mathrm{a}$ & $0.1 \pm 0 \mathrm{a}$ \\
\hline \multirow[t]{2}{*}{$\mathrm{C}_{\mathrm{i}}$} & WW & $262.26 \pm 5.55 b c$ & $256.78 \pm 4.3 \mathrm{bc}$ & $240.95 \pm 7.87 \mathrm{abc}$ & $258.9 \pm 3.12 b c$ & $248.1 \pm 5.31 b c$ & $255.87 \pm 6.26 b c$ \\
\hline & WDS & $233.09 \pm 15.53 \mathrm{ab}$ & $260.99 \pm 11.82 b c$ & $246.38 \pm 12.81 \mathrm{abc}$ & $246.65 \pm 15.35 \mathrm{abc}$ & $218.8 \pm 4.85 \mathrm{a}$ & $267.82 \pm 6.63 c$ \\
\hline \multirow[t]{2}{*}{$\mathrm{E}$} & WW & $4.68 \pm 0.33 c$ & $4.51 \pm 0.14 \mathrm{c}$ & $3.82 \pm 0.35 c$ & $4.7 \pm 0.18 c$ & $4.23 \pm 0.26 c$ & $4.32 \pm 0.24 c$ \\
\hline & WDS & $2.64 \pm 0.62 b$ & $2.13 \pm 0.29 \mathrm{ab}$ & $1.28 \pm 0.09 a$ & $1.64 \pm 0.33 a$ & $1.26 \pm 0.03 a$ & $1.71 \pm 0.09 a$ \\
\hline \multirow{2}{*}{ WUE $_{\mathrm{i}}$} & WW & $57.32 \pm 3.94 a$ & $60.84 \pm 2.53 a$ & $73.07 \pm 5.49 \mathrm{ab}$ & $58.72 \pm 2.5 a$ & $66.65 \pm 3.95 \mathrm{ab}$ & $62.21 \pm 4.14 \mathrm{a}$ \\
\hline & WDS & $84.43 \pm 6.51 b c$ & $70.31 \pm 7.8 \mathrm{ab}$ & $82.5 \pm 7.57 \mathrm{bc}$ & $80.85 \pm 10.41 b$ & $98.91 \pm 3.06 c$ & $67.85 \pm 3.52 \mathrm{ab}$ \\
\hline \multirow[t]{2}{*}{$\delta^{13} \mathrm{C}$} & WW & $-28.94 \pm 0.42 a$ & $-28.35 \pm 0.38 \mathrm{ab}$ & $-27.31 \pm 0.29 b c$ & $-28.31 \pm 0.17 \mathrm{ab}$ & $-28.45 \pm 0.24 \mathrm{ab}$ & $-27.1 \pm 0.52 b c$ \\
\hline & WDS & $-27.22 \pm 0.7 b c$ & $-27.18 \pm 0.38 b c$ & $-26.46 \pm 0.23 c$ & $-27.36 \pm 0.39 b c$ & $-26.62 \pm 0.41 c$ & $-26.82 \pm 0.52 c$ \\
\hline \multirow[t]{2}{*}{ RWC } & WW & $88.97 \pm 0.5 \mathrm{abc}$ & $85.91 \pm 1.11 \mathrm{a}$ & $90.33 \pm 1.44 \mathrm{abc}$ & $87.14 \pm 0.6 \mathrm{ab}$ & $87.05 \pm 1.64 \mathrm{ab}$ & $90.59 \pm 0.87 b c$ \\
\hline & WDS & $92.92 \pm 2.19 c$ & $92.2 \pm 1.01 c$ & $91.27 \pm 1.19 b c$ & $89.92 \pm 1.43 a b c$ & $87.66 \pm 0.74 a b$ & $91.38 \pm 0.67 b c$ \\
\hline \multirow[t]{2}{*}{$\Psi_{\mathrm{PD}}$} & WW & $-0.25 \pm 0.03 \mathrm{e}$ & $-0.28 \pm 0.02 \mathrm{cde}$ & $-0.39 \pm 0.04 \mathrm{abcd}$ & $-0.35 \pm 0.03 \mathrm{bcde}$ & $-0.27 \pm 0.03 \mathrm{de}$ & $-0.26 \pm 0.03 \mathrm{de}$ \\
\hline & WDS & $-0.4 \pm 0.03 a b c$ & $-0.38 \pm 0.04$ abcde & $-0.45 \pm 0.05 \mathrm{ab}$ & $-0.48 \pm 0.05 a$ & $-0.43 \pm 0.01 \mathrm{ab}$ & $-0.33 \pm 0.05 b c d e$ \\
\hline \multirow[t]{2}{*}{$\Psi_{\text {Mid }}$} & WW & $-1.22 \pm 0.09 \mathrm{abc}$ & $-1.26 \pm 0.04 a b$ & $-1.24 \pm 0.08 \mathrm{abc}$ & $-1.3 \pm 0.07 \mathrm{ab}$ & $-1.12 \pm 0.05 a b c$ & $-1.07 \pm 0.04 b c$ \\
\hline & WDS & $-1.12 \pm 0.02 \mathrm{abc}$ & $-1.18 \pm 0.17 a b c$ & $-1.31 \pm 0.07 \mathrm{ab}$ & $-1.39 \pm 0.1 \mathrm{a}$ & $-1.37 \pm 0.15 a b$ & $-0.96 \pm 0.03 c$ \\
\hline \multirow[t]{2}{*}{$K_{\text {plant }}$} & WW & $4.84 \pm 0.21 \mathrm{de}$ & $4.66 \pm 0.45 \mathrm{de}$ & $4.69 \pm 0.6 \mathrm{de}$ & $5 \pm 0.21 \mathrm{de}$ & $4.98 \pm 0.19 \mathrm{de}$ & $5.41 \pm 0.31 \mathrm{e}$ \\
\hline & WDS & $3.75 \pm 1$ bcde & $3.89 \pm 1.82 \mathrm{cde}$ & $1.6 \pm 0.32 \mathrm{ab}$ & $2.07 \pm 0.82 \mathrm{abc}$ & $1.39 \pm 0.19 a$ & $2.73 \pm 0.2 \mathrm{abcd}$ \\
\hline \multirow[t]{2}{*}{ LMA } & WW & $90.4 \pm 2.69 b c$ & $62.3 \pm 7 a$ & $78.8 \pm 3.22 \mathrm{ab}$ & $74.63 \pm 5.47 \mathrm{ab}$ & $84.3 \pm 1.14 b c$ & $77.67 \pm 6.41 \mathrm{ab}$ \\
\hline & WDS & $97.83 \pm 3.88 c$ & $82 \pm 3.92 b c$ & $76.75 \pm 3.37 \mathrm{ab}$ & $76.5 \pm 5.51 \mathrm{ab}$ & $82 \pm 3.18 b c$ & $78 \pm 2.75 \mathrm{ab}$ \\
\hline
\end{tabular}

$\mathrm{A}_{\mathrm{N}}$, Net photosynthesis $\left(\mu \mathrm{mol} \mathrm{CO} \mathrm{CO}^{-2} \mathrm{~s}^{-1}\right) ; \mathrm{g}_{\mathrm{s}}$, stomatal conductance $\left(\mathrm{mol} \mathrm{H}_{2} \mathrm{O} \mathrm{m}^{-2} \mathrm{~s}^{-1}\right) ; \mathrm{C}_{\mathrm{i}}$, substomatal $\mathrm{CO}_{2}$ concentration $\left(\mu \mathrm{mol} \mathrm{CO} \mathrm{CO}_{2} \mathrm{~mol}_{\text {air }}{ }^{-1}\right) ; \mathrm{E}$, transpiration $\left(\mathrm{mmol} \mathrm{H}_{2} \mathrm{O} \mathrm{m}^{-2} \mathrm{~s}^{-1}\right) ;$

WUE ${ }_{i}$ intrinsic water use efficiency ( $\left.\mu \mathrm{mol} \mathrm{CO} \mathrm{CO}_{2} \mathrm{~mol} \mathrm{H}_{2} \mathrm{O}^{-1}\right) ; \delta^{13} \mathrm{C}_{,}^{13} \mathrm{C}$ carbon isotope composition ratio(\%o); RWC, leaf relative water content $(\%)$; $\Psi_{\mathrm{PD}}$, leaf water potential at predawn

$(\mathrm{MPa}) ; \Psi_{\mathrm{Mid}}$, leaf water potential at midday $(\mathrm{MPa}) ; \mathrm{K}_{\text {plant }}$, whole plant hydraulic conductance $\left(\mathrm{mmol} \mathrm{H}_{2} \mathrm{O} \mathrm{m}^{-2} \mathrm{~s}^{-1} \mathrm{MPa}^{-1}\right)$; $\mathrm{LMA}$, leaf mass area $\left(\mathrm{g} \mathrm{m}{ }^{-2}\right)$. 


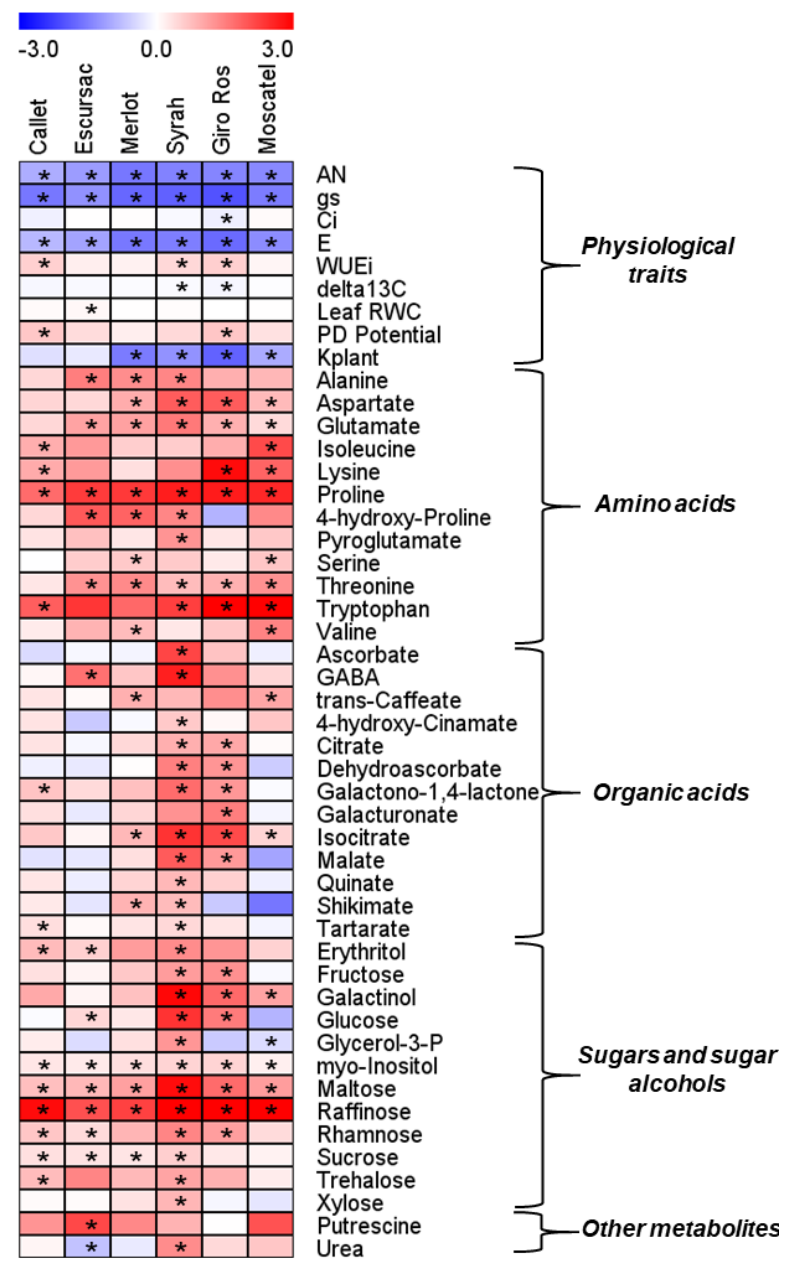

Figure 1. Heatmap of the physiological and metabolic responses to water deficit stress in all grapevine cultivars. Values are $\log 2$ transformed fold-changes calculated from water deficit stress (WDS)/well-watered (WW) ratios. The physiological parameters and metabolites shown were selected to have statistically significant $(p<0.05)$ differences between WDS and WW conditions in at least one of the cultivars. Asterisks denote significant changes $(p<0.05)$ determined after $t$-test comparisons between WDS and WW conditions. For abbreviations information see Table 1.

\section{Results}

\subsection{Physiological Traits and Responses under Well-Watered and Water Deficit Stress Treatments}

All six cultivars were grown in pots during late spring-summer season under Mediterranean conditions. In summer, all cultivars were subjected to two irrigation regimes, well-watered (WW) and water deficit stress (WDS) as defined by stomatal conductance (see Material and Methods for details). This ensured that plants were subjected to a similar level of physiological WDS within treatment. In WW treatment, the soil water content (SWC) was $51.6 \pm 2.7 \%$ with no significant differences among cultivars. Under WDS, the values were more variable; SWC dropped to values close to $27.7 \pm 0.8 \%$ with no differences among cultivars in Callet, Escursac and Moscatell. Merlot and Giró Ros fell to $23.1 \pm 2.7 \%$ and $18.4 \pm 1.4 \%$, respectively, and Syrah presented the lowest SWC $(16.3 \pm 2.21 \%)$ being significantly different to the rest of the cultivars except to Giró Ros.

Under WW conditions, little variation in net photosynthesis $\left(\mathrm{A}_{\mathrm{N}}\right)$ and stomatal conductance $\left(g_{s}\right)$ was observed among the different genotypes (Table 1$)$. Differences in the intrinsic water use efficiency $\left(W_{U E}\right)$ and ${ }^{13} \mathrm{C}$ carbon isotope composition $\left({ }^{13} \mathrm{C}\right)$ among genotypes were generally not statistically significant, except for the lower $\delta^{13} \mathrm{C}$ in Callet as compared to Merlot and Moscatel. Similarly, differences in internal $\mathrm{CO}_{2}$ concentration $\left(\mathrm{C}_{\mathrm{i}}\right)$ and transpiration $(\mathrm{E})$ among genotypes were 
not statistically significant. With regard to plant water relations, whole plant hydraulic conductance $\left(\mathrm{K}_{\text {plant }}\right)$ was also similar in all genotypes. Callet showed the highest leaf water potential at predawn $\left(\Psi_{\mathrm{PD}}\right)$ but only statistically significant when compared to Merlot, while Escursac displayed the lowest relative water content (RWC) although only statistically different from Moscatel. The index of sclerophylly, leaf mass per unit area (LMA), was also generally similar in all genotypes, except for Escursac which displayed the lowest LMA being statistically different from Giró Ros or Callet.

As expected, WDS significantly reduced $A_{N}, g_{s}$ and $E$ in all genotypes (Table 1). The $g_{s}$ was not statistically different between genotypes, thus indicating that the level of WDS was kept similarly mild among all cultivars. Among red cultivars, the local Callet and Escursac displayed significantly higher $\mathrm{A}_{\mathrm{N}}$ than the widespread Merlot, while Syrah displayed an intermediate $\mathrm{A}_{\mathrm{N}}$. Similarly, $\mathrm{E}$ was higher in both local Callet and Escursac than in the widespread ones, although differences were only statistically significant with Callet. On the other hand, differences in both parameters indicating water use efficiency, $W \mathrm{WE}_{\mathrm{i}}$ and $\delta^{13} \mathrm{C}$, were not statistically significant among red cultivars. With regard to water status, leaf relative water content (RWC), as well as both water potentials (predawn and midday), were not significantly different between local and widespread red cultivars. On the other hand, Callet and Escursac displayed high plant hydraulic conductance $\left(\mathrm{K}_{\text {plant }}\right)$ although statistically significant differences were only detected between Escursac and Merlot. Finally, LMA under WDS was higher in the local cultivars Callet and Escursac than in the widespread ones, being significant in the case of Callet. Altogether, results denote that despite all cultivars were subjected to a similar WDS, local red cultivars displayed a better physiological performance as compared to the widespread red ones. With regard to white cultivars, the local cultivar, Giró Ros, displayed higher $W_{U E}$ as compared to the widespread Moscatel, despite displaying a lower leaf water potential at midday ( $\Psi_{\mathrm{MD}}$ ).

In order to evaluate the responsiveness to WDS, the fold-changes from WW to WDS were evaluated and compared among cultivars (Figure 1). Despite the significant reductions in $\mathrm{A}_{\mathrm{N}}, \mathrm{g}_{\mathrm{s}}$ and $\mathrm{E}$ observed in all genotypes, only Callet, Syrah and Giró Ros displayed a statistically significant $(p<0.05)$ increase in $W_{U E}$ while Syrah and Giró Ros also increased their $\delta^{13} \mathrm{C}$, both parameters indicating an increase in water use efficiency. In this line of responsiveness, only Callet and Giró Ros displayed a significant decrease (more negative) in their $\Psi_{\mathrm{PD}}$. Finally, the $\mathrm{K}_{\text {plant }}$ decreased in all genotypes except in the local red cultivars Callet and Escursac.

\subsection{Multivariate Analysis of the Metabolite Levels under Well-Watered and Water Deficit Stress Treatments}

The metabolic differences in the six cultivars under WW and WDS conditions were investigated using GC-TOF-MS based metabolite profiling. A total of 53 metabolites including 15 amino acids, 22 organic acids, 14 sugars and sugar alcohols and two other metabolites were annotated in leaves of all six cultivars and in both treatments (Table S1). Firstly, we performed a Principal Component Analysis and the first component (PC1) separated the cultivars according to the irrigation treatment and explained $50 \%$ of the variance from the metabolite profiling data (Figure 2A). Among metabolite classes, several amino acids and related metabolites (lysine, alanine, threonine, pyrogutamate, isoleucine, serine, GABA, glutamate, proline, tryptophan, hydroxy-proline, urea, aspartate and valine) were mainly responsible for samples dispersion along PC1 ( $\mathrm{r}^{2}$ coefficient $\geq 0.7$, Table S4, Figure 3), followed by sugar and derivates (maltose, rhamnose, erythritol, glycerol-3-P, myo-inositol, raffinose, sucrose, glycerol, fructose-6-P, galactinol and fructose), and organic acids (isocitrate, citrate, 3-P-glycerate, trans-caffeate, ascorbate, cis-caffeate, galactono-1,4-lactone, 2-oxoglutarate, dehydroascorbate). The PC2 only explained a $16 \%$ of the variance and separated some genotypes from others, with only galacturonate, beta-alanine, glycine, and phenylalanine being the metabolites displaying a high $\mathrm{r}^{2}$ coefficient $(\geq 0.7)$ with PC2 (Table S4). 


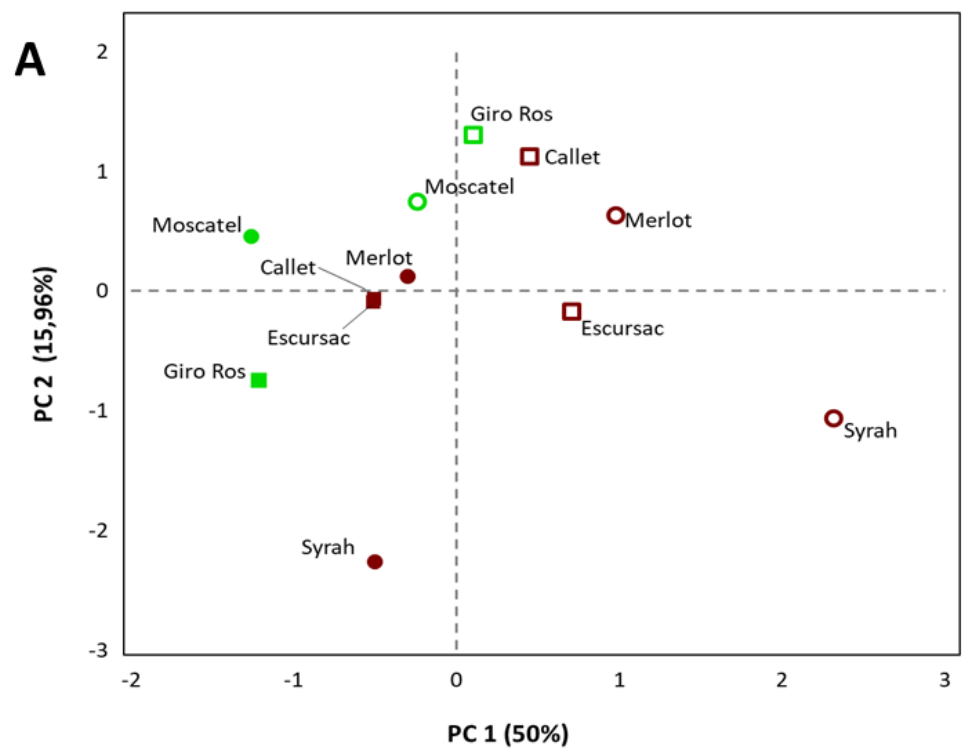

B

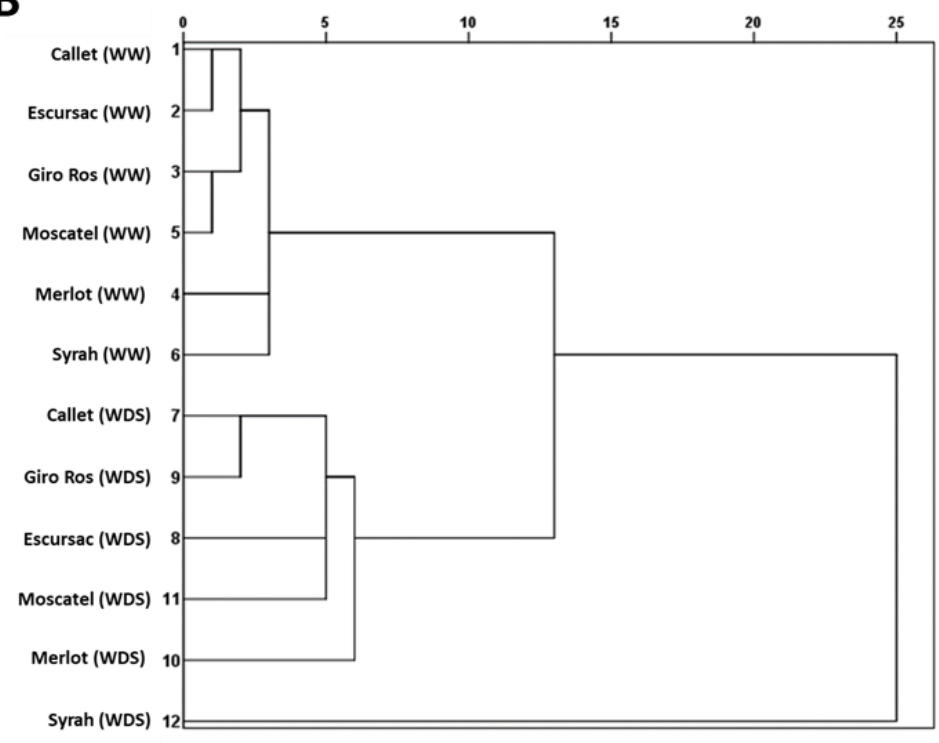

Figure 2. Multivariate analysis of metabolic changes associated with cultivar and water deficit stress. (A) Principal component analysis (PCA) of grapevine varieties under well-watered (WW) and water deficit stress (WDS) treatments. Filled/empty symbols means WW/WDS conditions respectively. Circles/squares means widespread/local varieties respectively and maroon/green colors means red/white varieties. (B) Dendrogram showing distributions, distances and the grouping among the different cultivars and water treatments using all the metabolite data.

Next, we performed a multivariate cluster analysis in order to identify which genotypes display similar metabolic profiles and whether this separation is in line with the observed physiological differences (Figure 2B). In this sense, dendrogram separated the local cultivars (Callet, Escursac and Giró Ros) from the widespread ones under both WW and WDS conditions. This suggests that local cultivars have genotype-specific metabolic differences that could underlie the observed different physiological responses to WDS. With regard to the stress treatment, all cultivars under WW conditions clearly clustered away from those under WDS. 

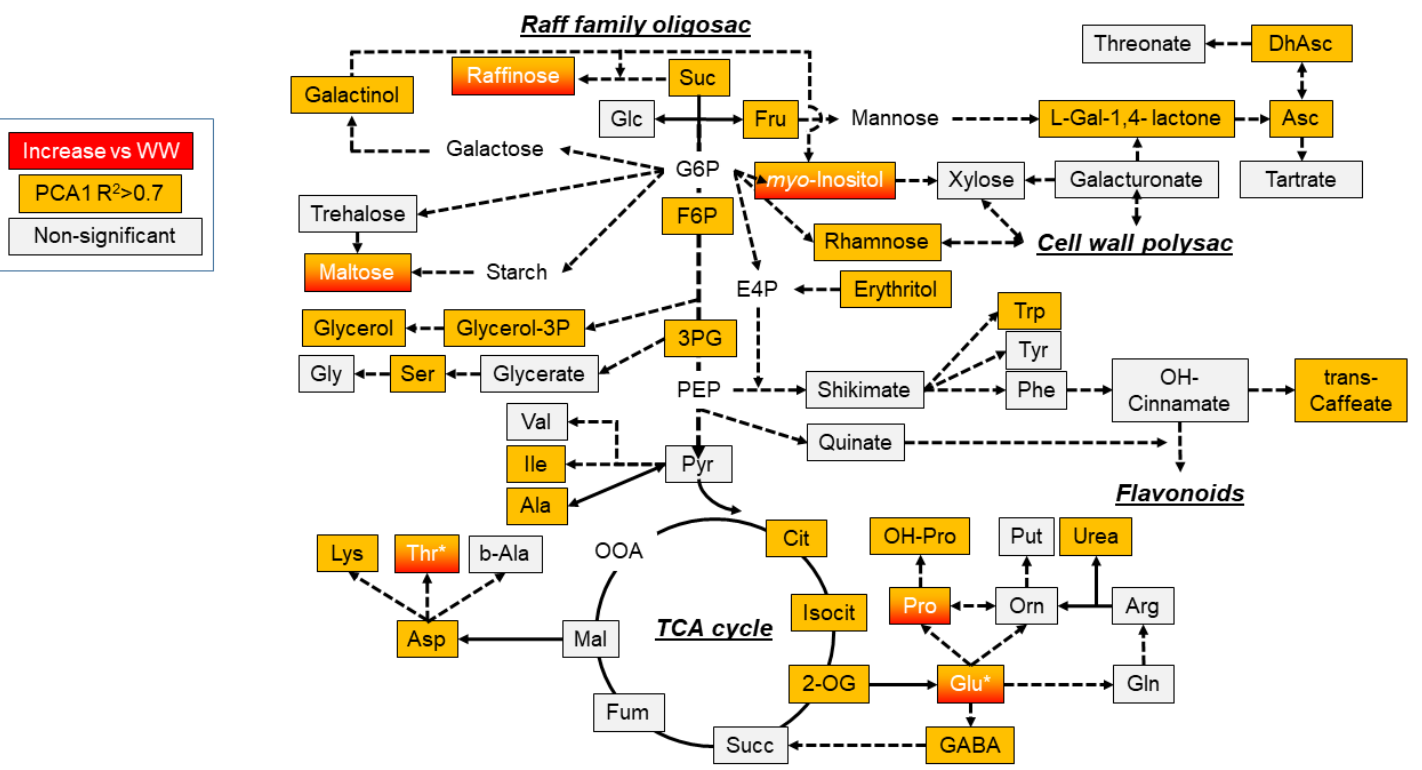

Figure 3. Common changes in leaf primary metabolism under water deficit stress (WDS) in all cultivars. Metabolites colored are those showing statistically significant $(p<0.05)$ increases in all cultivars (red) under WDS, and with a $\mathrm{r}^{2}>0.7$ associated to the principal component 1 (orange). Data used was taken from Figure 1 and Table S4. Suc, sucrose; Glc, glucose; Fru, fructose; G6P, glucose-6-phosphate; F6P, fructose-6-phospate; E4P, erythrose-4-phospate; 3PG, 3-phosphoglycerate; PEP, phosphoenolpyruvate; Pyr, pyruvate; Cit, citrate; Isocit, isocitrate; 2-OG, 2-oxo-glutarate; Succ, succinate; Fum, fumarate; Mal, malate; OOA, oxaloacetate; Asp, aspartate; Lys, lysine; Thr, threonine; b-Ala, beta-alanine; Val, valine; Ile, isoleucine; Ala, alanine; Ser, serine; Gly, glycine; Glycerol-3P, glycerol-3-phosphate; Glu, glutamate; GABA, gamma-aminobutyrate; Pro, proline; OH-Pro, 4-hydroxy-proline; Orn, ornithine; Gln, glutamine; Arg, arginine; Put, putrescine; Trp, tryptophan; Tyr, tyrosine; Phe, phenylalanine; $\mathrm{OH}$-Cinamate; 4-hydroxy-cinnamate; L-Gal-1,4-lactone, L-galactone-1,4-lactone; Asc, ascorbate; DhAsc, dehydroascorbate. *Metabolites significantly $(p<0.05)$ increasing under WDS with the exception of Callet.

\subsection{Metabolite Profiling and Responses under Well-Watered and Water Deficit Stress Treatments}

As for the physiological data, we calculated the metabolite fold-change responses to WDS in all cultivars (Figure 1) in order to evaluate the responsiveness among the different cultivars. In general, several amino acids, as well as sugars and sugar alcohols, were significantly increased in all genotypes while organic acids were less responsive. The following common and significant increases after WDS were observed in all genotypes: myo-inositol, maltose, raffinose and proline as well as glutamate and threonine (with the exception of Callet; Figures 1 and 3).

With regard to red cultivars, Syrah was displaying, by far, the highest number (thirty-three) of significantly changed metabolites after WDS treatment (Figure 1). In Merlot, fourteen metabolites significantly increased after WDS, being all these metabolites shared with Syrah except Serine and Valine. Notably, changes in amino acid profiles were very similar in Merlot and Syrah while much less organic acids, sugars and sugar alcohols were significantly changed in Merlot as compared to Syrah. The local red cultivars displayed lower numbers of significantly changed metabolites, twelve and fourteen in Callet and Escursac, respectively (Figure 1). While several of the metabolites changing in local cultivars were similar to those changing in the widespread ones, there were some exceptions. Aspartate, isocitrate and shikimate (trans-caffeate only in Merlot although Syrah displayed a very similar trend) were significantly increased only in widespread cultivars after WDS (Figures 1 and 4). On the other hand, lysine and isoleucine only increased in Callet (a similar trend in Escursac), and putrescine only significantly increased in Escursac (Figures 1 and 4). Finally, urea significantly decreased only in Escursac while the opposite was observed in Syrah (Figure 1). 


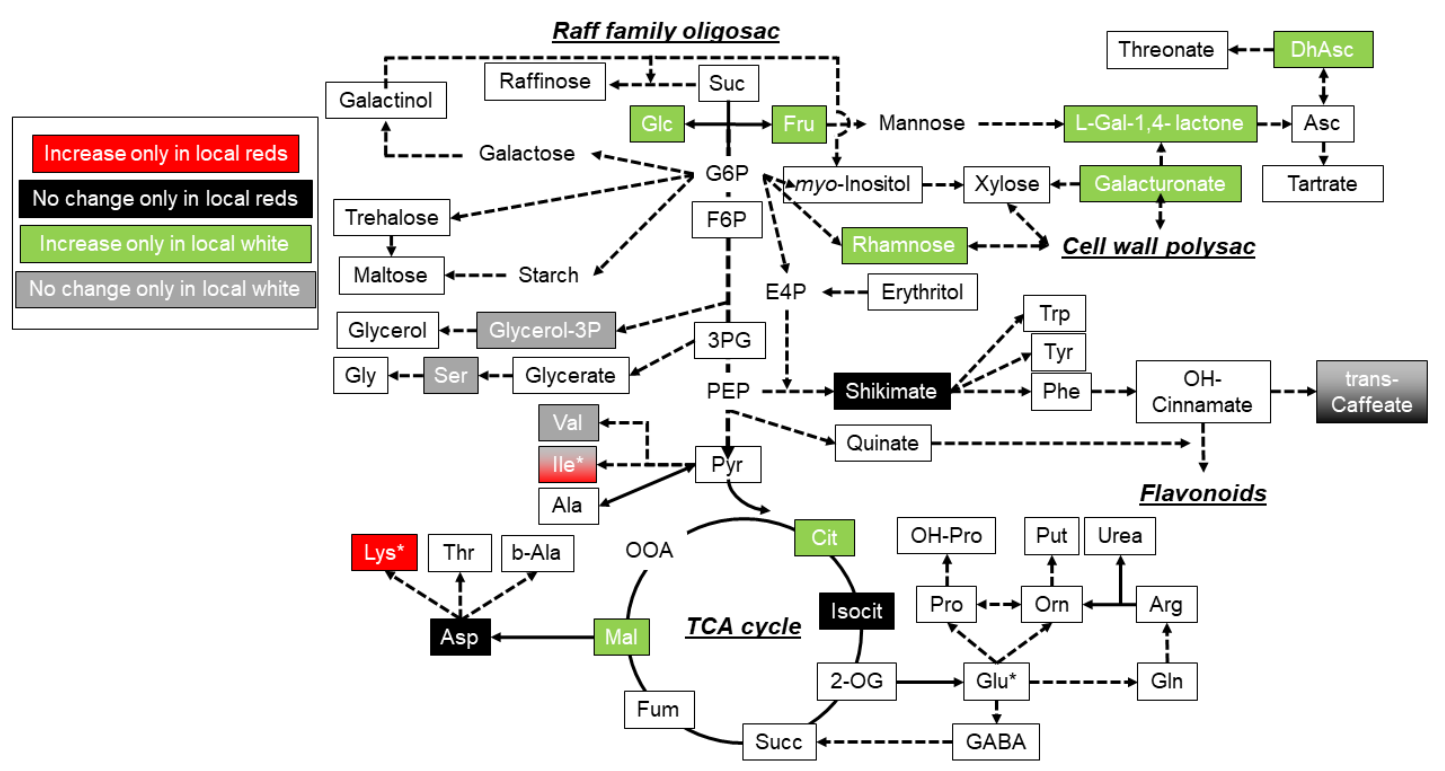

Figure 4. Metabolic model showing differences in the water deficit stress (WDS) response of leaf primary metabolism between widespread and local cultivars. Metabolites highlighted are those showing significant $(p<0.05)$ increase only in both local red (red) or in the local white (green) cultivars as compared to their corresponding widespread ones. Metabolites not significantly changing $(p>0.05)$ only in local red (black) and white (grey) cultivars (i.e., only significantly changing in widespread cultivars) are also highlighted. Data used was taken from Figure 1. For the metabolite abbreviations see Figure 3. *Only significantly $(p<0.05)$ increased in Callet although Escursac displayed a very similar trend.

With regard to white cultivars, the number of significantly changed metabolites after WDS was similar between Giró Ros (nineteen) and Moscatell (sixteen), although the profiles were notably different (Figure 1). Giró Ros displayed a higher number of increased organic acids (citrate, dehydroascorbate, galactono-1,4-lactone, galacturonate and malate) and sugars (fructose, glucose and rhamnose) than Moscatel (Figures 1 and 4). On the other hand, isoleucine, serine and valine were only significantly increased in Moscatel, although the remaining six amino acids (aspartate, glutamate, lysine, proline, threonine and tryptophan) were increased in both cultivars (Figures 1 and 4). When compared to red cultivars, increases in lysine and tryptophan were more pronounced in the white cultivars (Figure 1 and Table S3). Finally, while sucrose was significantly increased in all red cultivars, it was not significantly increased in white cultivars after WDS (Figure 1).

The relative levels of metabolites under WDS were next directly compared among genotypes (Table S3). Syrah was the cultivar showing the largest differences in the metabolic profiles (Table S3). Syrah displayed the highest levels of all amino acids except for tryptophan, for which the highest levels were detected in Callet. Also, the levels of several organic acids and sugars were higher in Syrah than in the other cultivars. Notably, some metabolites displayed similar levels among local red cultivars, while being different from the red widespread ones. Dehydroascorbate, quinate, erythritol, fructose and glycerol were lower in both local red cultivars than in both widespread ones (Table S3 and Figure 5). With regard to white cultivars, both displayed significantly lower levels of fructose-6-P when compared to red cultivars (except with Callet). In addition, shikimate and sucrose were significantly lower in Giró Ros than in red cultivars while Moscatel displayed intermediate levels (Table S3). Finally, the levels of proline, isocitrate, malate, maltose and raffinose were higher in Giró Ros than in Moscatel, while the opposite was observed for the levels of glycerate and threonate (Table S3 and Figure 5). 


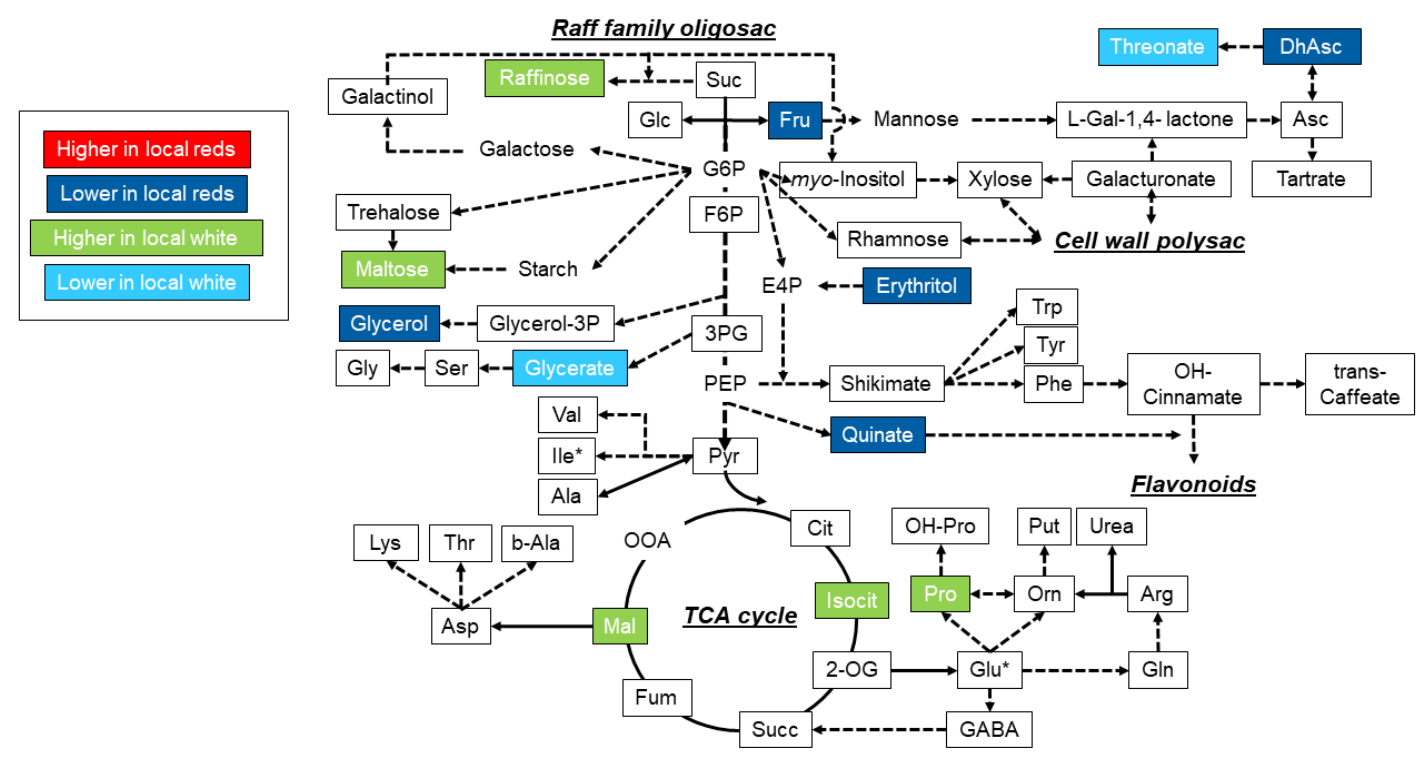

Figure 5. Metabolic model showing differences in the levels of leaf primary metabolites between widespread and local white cultivars under water deficit stress (WDS). Metabolites highlighted are those showing significantly $(p<0.05)$ higher or lower levels in local red (red or dark blue) and local white (green or light blue) cultivars as compared to their corresponding widespread ones. Data used was taken from Table S3. For the metabolite abbreviations see Figure 3.

\subsection{Correlations between Physiological Parameters and Metabolite Levels under Water Deficit Stress}

Correlations between physiological parameters and metabolite levels were performed (Tables S5 and S6) for an explorative analysis of which physiological parameters were associated with a particular metabolic response in local and widespread cultivars under WDS. Correlations were performed with data sets of red (Table S5) and white (Table S6) cultivars separately. When considering all metabolite correlations with each physiological parameter together, a FDR correction of the $p$-values was applied to correct for multiple comparisons (for further details, see the Materials and Methods section), thus excluding false-positive Pearson correlation coefficients (i.e., values highlighted both in bold and with an asterisk in Tables S5 and S6). In general, most of the significant correlations in red cultivars were negative while the opposite was observed in white cultivars (Tables S5 and S6). On the other hand, metabolites correlating with the different physiological parameters were very different between red and white cultivars (Tables S5 and S6).

As previously commented in Section 3.1, the physiological parameters displaying differences between local and widespread red cultivars were $\mathrm{A}_{\mathrm{N}}, \mathrm{E}, \mathrm{K}_{\text {plant }}$ and LMA (Table 1 and Figure 1). Notably, $\mathrm{A}_{\mathrm{N}}$ displayed significant $(p<0.05)$ and negative correlations with dehydroascorbate, quinate, erythritol, fructose and myo-inositol after FDR correction (Table S5), being almost the same metabolites identified to be consistently lower in the local than in the widespread cultivars (Table S3 and Figure 5). Very similar metabolites were also identified correlating with E (Table S5). On the other hand, erythritol, rhamnose and maltose correlated significantly $(p<0.05)$ with $\mathrm{K}_{\text {plant }}$ after FDR correction (Table S5). Regarding LMA, this parameter displayed the highest number of metabolite significant $(p<0.05)$ correlations after FDR correction (Table S5), which included the previously observed in $\mathrm{A}_{\mathrm{N}}, \mathrm{E}$ and $\mathrm{K}_{\text {plant }}$ and several additional ones (glucose, fructose-6-P, 3-P-glycerate, glycerol-3-P, 2-oxo-glutarate, rhamnose, glutamate, pyroglutamate, 4-hydroxy-proline, succinate, threonine, glycerol, alanine and pyruvate).

In white cultivars, the physiological parameters displaying differences between local and widespread cultivars were $W E_{i}$ and $\Psi_{M D}$ (Table 1 and Figure 1). WUE $E_{i}$ displayed significant positive correlations with maltose, raffinose, and malate after FDR correction (Table S6), being almost the same metabolites identified to be consistently higher in the local than in the widespread cultivar (Table S3 and Figure 5). WUE $\mathrm{i}_{\mathrm{i}}$ also displayed significant negative correlations with threonate, tartrate 
and shikimate (Table S6). On the other hand, $\Psi_{\mathrm{MD}}$ displayed significant positive correlations with glycine and threonate while negative correlations with proline and malate (Table S6).

\section{Discussion}

The natural variability existing in cultivars that are locally better adapted to the Mediterranean region constitutes formidable genetic material to study contrasting grapevine behaviors or responses to climate change, particularly to water deficit stress (WDS). In the present study, physiological and metabolic traits have been characterized in leaves of local and widespread cultivars including four red and two white genotypes. All cultivars were subjected to a similar physiological level of WDS as determined by stomatal conductance measurements [46]. The mild level of WDS applied to all genotypes was also denoted by different water status parameters such as leaf relative water content, predawn and midday water potentials (Table 1$)$.

Under well-watered (WW) conditions, local and widespread cultivars displayed few physiological differences, however, a different responsiveness to WDS was observed between them (Table 1, Figure 1). As expected, WDS conditions restricted physiological parameters in all genotypes, however, the local red cultivars showed higher net photosynthesis $\left(\mathrm{A}_{\mathrm{N}}\right)$ than the widespread red counterparts. Indeed, $A_{N}$ decrease was lower than $60 \%$ in the locals Callet and Escursac, while Merlot and Syrah showed a $67 \%$ and $64 \%$ decrease, respectively. The maintenance of a higher $A_{N}$ despite similar $g_{s}$ suggests that either metabolic or other diffusional limitations, such as mesophyll conductance $\left(g_{m}\right)$, may have been less limiting in the local cultivars. Moreover, red wide-distributed cultivars significantly reduced their plant hydraulic conductance $\left(K_{\text {plant }}\right)$ under WDS, while local ones did not. The hydraulic conductance is one of the key physiological factors in stomatal regulation in grapevine and a cultivar dependent relationship has been demonstrated [55]. The higher $\mathrm{K}_{\text {plant }}$ observed in the local cultivars suggests greater ability of Callet and Escursac to maintain turgor at low water potentials, leading to better hydraulics at a similar stomatal conductance. The high $\mathrm{K}_{\text {plant }}$ kept by local cultivars under WDS could explain their higher photosynthetic rates, probably due to a higher $\mathrm{g}_{\mathrm{m}}$ since a positive relationship between leaf hydraulic conductivity (related to $\mathrm{K}_{\text {plant }}$ ) and $\mathrm{g}_{\mathrm{m}}$ has been reported [56]. With regard to WUE, Callet showed the highest increase in $\mathrm{WUE}_{\mathrm{i}}(47.3 \%)$, although both $\mathrm{WUE}_{\mathrm{i}}$ and $\delta^{13} \mathrm{C}$ under WDS were not statistically different among all red cultivars. These data show that improving WUE may not necessarily result in decreased $\mathrm{A}_{\mathrm{N}}$ and productivity, and local cultivars like Callet or Escursac can be good candidates to achieve simultaneous improvements of photosynthesis and WUE. Likewise, Syrah also displayed a significant increase in $W_{U E}$ as an effect of WDS, probably due to its strong control of $g_{s}$ that finally yielded in an intermediate $A_{N}$. With regard to white varieties, the local Giró Ros was able to maintain a similar $\mathrm{A}_{N}$ than the widespread Moscatel despite its larger decrease in $\mathrm{g}_{\mathrm{s}}$, which led to a much higher and significant WUE increase (48.5\%) as compared to Moscatel $(9 \%)$. Again, these results do not match the general view that increasing WUE implies reductions in $A_{N}$ and hence less yield. Flexas et al., [56] also supported the hypothesis that it might be possible to simultaneously increase photosynthesis and WUE in grapevine by means of improving $g_{m}$ over $g_{s}$. Nevertheless, other physiological processes can be involved in $\mathrm{A}_{\mathrm{N}}$ increases. For instance, whether chloroplast biochemical limitations such as changes in Rubisco, Calvin cycle, electron transport chain or aquaporin activities are also involved in the ameliorated $\mathrm{A}_{\mathrm{N}}$ in these local cultivars under WDS deserves further investigation involving more extensive photosynthetic analyses. To this respect, evidence for better WDS performance in Majorcan local cultivars has been described in terms of their photosynthetic characteristics, water relations and water use efficiency [10,13,57]. Bota et al. [13] observed, in irrigated potted plants, that the Majorcan cultivars, Callet, Premsal Blanc and Sabater, presented higher assimilation rates than two internationally cultivated cultivars (Cabernet Sauvignon and Chardonnay). Moreover, the local cultivar Escursac was found to be an interesting cultivar to maintain reasonably high carbon assimilation and low water consumption, resulting in high WUE both under drought and irrigation [13]. However, in our experimental results, Escursac did not show a large WUE increase in WDS conditions. On the other hand, the behavior observed in the white 
cultivar Giró Ros was very similar to the one described by Bota et al., [10] under progressive drought field conditions; i.e., a strong water-saving behavior with high values of $\mathrm{WUE}_{\mathrm{i}}$ and $\delta^{13} \mathrm{C}$. Clearly, the local white cultivar Giró Ros reached high $W_{U E}$ due to a strong reduction in $g_{s}$, probably caused by the reduction in $\mathrm{K}_{\text {plant. }}$. In this sense, this cultivar showed a clear different behavior to the red local cultivars Callet and Escursac. Moreover, no changes in LMA were observed in Giró Ros, while Escursac (similar trend in Callet) displayed an increase in LMA under WDS. The increase in LMA is usually a consequence of an increase in density or thickness of foliar tissue and normally occurs when leaves are developed under low water availability [58]. A strong positive relationship was reported between WUE $\left(\delta^{13} C\right)$ and LMA [59]. However, we did not observe this relationship in our study since Callet and Giró Ros displayed WDS-induced changes in $\delta^{13} \mathrm{C}$ while LMA was not significantly affected. Therefore, other factors must be involved. Nevertheless, these results can be used as a basis for future studies under field conditions, not only to corroborate the physiological responses observed but also to investigate the effects of such responses on yield, quality or even in plant survival. Indeed, there is evidence that stomatal sensitivity of different cultivars is an important feature for increasing summer drought adaptation [19]. It is clear both from previous studies and the present results that the differential stomatal control, mesophyll-stomata interactions, photosynthesis, and its implications in WUE are complex and involve multiple mechanisms and signaling responses. In this respect, while different metabolomics approaches have been widely recognized as key to understanding drought tolerance mechanisms, the variability of primary metabolism responses to WDS comparing local and widespread cultivars deserves to be explored.

Previously, Hochberg et al. [43] studied grapevine leaf primary and secondary metabolism in response to WDS in two widespread cultivars with different hydraulic behaviors, Syrah and Cabernet Sauvignon. An accumulation of amino acids and sugar alcohols with osmoprotective and antioxidant roles was reported in both grapevine cultivars under WDS [43]. Their principal component (PC) analysis highlighted proline, galactinol, glycerate and galactonate (an ascorbate-related metabolite) as those mainly responsible for the separation of samples according to their irrigation treatment [43]. In close agreement, our principal component analysis denoted stress-related amino acids (including proline, 4-hydroxy-proline, threonine and GABA), organic acids (including ascorbate, galactono-1,4-lactone and dehydroascorbate) as well as stress-related sugars and derivatives (including raffinose, myo-inositol, sucrose and galactinol) as the main responsible for the separation of WW from WDS samples in PC1 (Figure 2A and Table S4). Recently, Degu et al. [42] have observed a drought-induced up-regulation of proline, GABA and stress-related sugar metabolism at the transcript and metabolite levels in Merlot leaves. Such observations are also in line with the significant increases in the levels of proline, myo-inositol, maltose and raffinose observed here in all genotypes after WDS (Figures 1 and 3). In addition, glutamate together with branched chain (valine, isoleucine) and aspartate family (aspartate, lysine and threonine) amino acids also displayed high correlation coefficients with the PC1 from our study (Table S4). These amino acids can be used as alternative substrates for energy production under stress conditions, via direct oxidation to feed electrons into the mitochondrial electron transport chain or via their catabolism into tricarboxylic acid (TCA) cycle intermediates [60]. In relation to the last, TCA cycle intermediates such as citrate, isocitrate and 2-oxo-glutarate were also in the list of metabolites with high correlation to PC1 (Table S4). In the same list, we also found starch degradation (maltose) and glycolytic (3-P-glycerate, fructose-6-P) products. Overall and considering that PC1 explained 50\% of the variance from the metabolite profiling data, our results suggest a strong and common metabolic response to drought in grapevine leaves, which is related to the activation of metabolic pathways for oxidative and osmotic stress release as previously suggested $[42,43]$ as well as to central and alternative catabolic pathways for energy metabolism (Figure 3).

Despite the common metabolic responses observed in all cultivars, our cluster analysis clearly separated local from widespread cultivars under both WW and WDS conditions, thus suggesting metabolic differences that could underlie their different physiological status and/or response to WDS. A clear genotype-specific response was observed in the case of Syrah in comparison to the rest of 
cultivars. The number of metabolites responding to WDS in Syrah was higher than in all the other cultivars (Figure 1), thus reaching the highest levels of amino acids and most organic acids and sugars (Table S3). This is in agreement with previous observations describing a greater metabolic response in Syrah as compared to Cabernet Sauvignon at leaf [43] and berry skin [39] tissues. Notably, the WDS level applied in the mentioned previous studies was severe and different between Syrah and Cabernet Sauvignon, i.e., Syrah displayed much lower $\mathrm{g}_{\mathrm{s}}$ and water potentials than Cabernet Sauvignon [43]. In our study, we compared all genotypes at a similar WDS level and the particular metabolic response of Syrah was still evident.

Our study involved red as well as white cultivars. Metabolic and transcriptional differences between red and white cultivars have been mainly explored at the berry level ([61] and references therein, [62] and references therein) while leaf studies remain rare and, to the best of our knowledge, not related to WDS [63]. In our study, sucrose levels were increased after WDS in red but not in white cultivars, from which generally sucrose levels were lower under WDS. Fructose-6-P and shikimate levels were also generally lower in white than in red cultivars. Given that $\mathrm{A}_{\mathrm{N}}$ was similarly reduced in red and white cultivars under WDS, which denotes a similar carbon limitation, the mentioned metabolic differences could indicate a higher use of the glycolytic intermediates (i.e., sucrose and fructose-6-P) for respiration or for the synthesis of specialized metabolites (or both), the last perhaps also explaining the lower shikimate levels observed in white cultivars. Differences in specialized metabolism between red and white cultivars have been extensively studied in berries and are not only due to anthocyanin contents but also the contents of other flavonoids ([61] and references therein; [62] and references therein). On the other hand, the network analysis performed by Degu et al. [61] denoted that central and specialized metabolism were more connected in red than in white cultivars, although primary metabolism was not specifically and broadly targeted. Given the evidence on the interdependence between primary metabolic fluxes and anthocyanin biosynthesis in tomato fruit [64] and grapevine cells [65], changes in primary metabolism between berries of red and white cultivars are expected. Whether this is also observed at the leaf level, as our study suggests, deserves further research involving more detailed analysis of metabolic fluxes [64,65]. Finally, the very different correlations between metabolites and physiological parameters as well as their opposite general trends (mostly negative in white while mostly positive in red cultivars) (Tables S5 and S6) also suggest that white and red cultivars displayed different metabolic and physiological adaptations to WDS.

Among red cultivars, Syrah clustered together with Merlot and away from the local cultivars (Figure 2B) despite displaying the most WDS-responsive metabolic profile. The differences in the WDS response or levels of erythritol and shikimate denotes specific changes in the shikimate pathway between local and widespread red cultivars (Figures 4 and 5), which potentially affected the synthesis of the aromatic amino acids and many derived specialized metabolites [66]. In line with our observations, WDS-induced changes in leaf specialized metabolites were reported to be cultivar-dependent [43]. Moreover, changes in quinate and trans-caffeate observed here may denote an alteration of the phenylpropanoid pathway that was also previously reported in Syrah as compared to Cabernet Sauvignon [43]. These changes were suggested as being potentially related to enhanced suberin synthesis in vascular tissues thus affecting plant water transport in response to WDS [43]. In our study, $K_{\text {plant }}$ significantly decreased in all genotypes except in the local Callet and Escursac (Table 1). In addition, erythritol and rhamnose, the last being a sugar used as a cell wall component, were among the few metabolites significantly correlating with $\mathrm{K}_{\text {plant }}$ (also with LMA) in red cultivars (Table S5). Recently, drought-induced changes in cell wall-related metabolites in tobacco leaves have been associated to improvements in $\mathrm{g}_{\mathrm{m}}$ and photosynthesis [67]. In addition, Roig-Oliver et al. [68] have recently suggested that stress-related cell wall modifications in grapevine (var. Grenache) can play a significant role in leaf physiology by affecting distinctly photosynthesis and water relations. Altogether, our results may denote different links between anatomical and metabolic changes that could be beneficial for the water relations in local cultivars. Nevertheless, several flavonoids derived from the phenylpropanoid pathway are involved in the avoidance of oxidative stress and in photoprotection, 
i.e., anthocyanins [69], the levels of which can be highly variable in berries of different cultivars [61]. In fact, the lower leaf levels of dehydroascorbate observed in local cultivars (Figure 5) can denote their lower oxidative stress, which could be mediated by a higher reducing capacity, i.e., through a higher ASC-GSH cycle activity [70]. The antioxidant biochemical strategies of local varieties in response to WDS deserves further research. Furthermore, $\mathrm{A}_{\mathrm{N}}$ displayed significant correlations with dehydroascorbate, erythritol and quinate (Table S5), thus reinforcing the idea of a link between changes in redox and shikimate/phenylpropanoid metabolism with the different photosynthetic performance observed in widespread and local cultivars under WDS.

With regard to white cultivars, metabolic changes between local and widespread plants were largely different from those observed in red cultivars (Figures 4 and 5). For instance, no specific differences on the shikimate and phenylpropanoid precursors were detected between local and widespread white cultivars. While shikimate and phenylpropanoid metabolism would be expected to behave differently in red and white berries as discussed above, the reason for these differences at the leaf level remain elusive. Nevertheless, the physiological parameters that differ between local and widespread plants were different in red (i.e., $\mathrm{A}_{\mathrm{N}}, \mathrm{E}, \mathrm{K}_{\text {plant }}$ and LMA) and in the white cultivars $\left(W_{U E}\right.$ and $\left.\Psi_{M D}\right)$. As commented above, the local white cultivar Giró Ros displayed clear different physiological behavior to the red local cultivars Callet and Escursac in relation to $K_{\text {plant }}, W_{E_{i}}$ and LMA. From this perspective, it is reasonable to expect different local vs. widespread metabolic behaviors in between red and white cultivars. The local Giró Ros did not display a better $A_{N}$ than the widespread Moscatel, as for the case in red cultivars. However, the higher WUE observed in the Giro Ros denotes that local plants were able to perform relatively better under WDS. Notably, the TCA cycle intermediates citrate, isocitrate and malate displayed higher levels/responses in Giró Ros, which could indicate the activation of respiratory pathways involved in osmotic stress tolerance including stomatal conductance regulation and the production of oxidative/osmotic stress protective metabolites [71-73]. In this line, the higher levels of proline and raffinose under WDS together with a higher response in ascorbate-related metabolites (dehydroascorbate, galactono-1,4-lactone and galacturonate) (Figures 4 and 5) denotes stress-related metabolic adaptations in Giró Ros that could help to maintain a similar $A_{N}$ than Moscatel in spite of having a lower $\Psi_{\mathrm{MD}}$.

\section{Conclusions}

Primary metabolism of local and widespread cultivars including red and white varieties was studied under mild water deficit stress (WDS) together with gas exchange, water relations and water use efficiency (WUE). Both red and white local cultivars displayed a different physiological performance, probably more adapted, under WDS as compared to widespread ones. In agreement, cluster analysis indicated that local cultivars have a differential metabolic response to WDS that could underlie the observed differences at the physiological level. Our integrative approach suggests that changes in ascorbate-related and shikimate/phenylpropanoid metabolism could explain both the better photosynthetic performance and water relations observed in red local (Callet and Escursac) as compared to widespread (Merlot and Syrah) cultivars. On the other hand, red and white cultivars displayed leaf metabolic differences that may resemble those expected at the berry level, which could be related to respiratory and/or flavonoid metabolism. Finally, the white local cultivar (Giró Ros) displayed changes in respiratory (TCA cycle) intermediates in concert with stress-related sugars (i.e., raffinose) and amino acids (i.e., proline) which could underlie its better WUE under WDS as compared to the white widespread cultivar (Moscatel). The results presented here thus suggest several metabolic targets that could be enhanced or introduced into grapevine varieties in attempt to metabolically engineer them to be drought tolerant. 
Supplementary Materials: The following are available online at http://www.mdpi.com/2073-4395/10/7/1052/s1, Table S1: Overview of the metabolite reporting list; Table S2: $p$-values associated with the factors cultivar, treatment and its interaction from the univariant Analysis of Variance (ANOVA); Table S3: Relative metabolite levels in leaves of all grapevine cultivars under well-watered (WW) and water deficit stress (WDS) conditions; Table S4: Factor loadings of the Principal components (PC) Analysis; Table S5: Pearson correlation coefficients between metabolite levels and physiological parameters in red cultivars under water deficit stress; Table S6: Pearson correlation coefficients between metabolite levels and physiological parameters in white cultivars under water stress. Table S7: Whole data set including all the individual replicates for all metabolites and physiological parameters determined.

Author Contributions: Conceptualization, J.B., M.J.C.-M., J.C. and I.F.-S.; Design of the experiment and methodology, J.B., M.J.C.-M.; Measurement, M.J.C.-M., J.B., I.F-S., and M.C.; Data Analysis, I.F.-S., M.J.C.-M., J.C., M.L. and J.B.; Statistical analysis, J.C., M.L. and I.F.-S.; Writing-Original Draft Preparation, M.J.C.-M. and I.F.-S.; Writing-Review \& Editing, I.F.-S., M.J.C.-M., J.B., J.C. and A.R.F.; Funding Acquisition, J.C. and J.B. All authors have read and agreed to the published version of the manuscript.

Funding: This research was funded by the project RTA2013-00068-C03-03 (INIA and FEDER funds) from Ministerio de Economía y Competitividad (MINECO, Spain). I.F.-S. has received funding from the European Union's Horizon 2020 research and innovation programme under the Marie Skłodowska-Curie grant agreement no. 753301'. M.J.C.-M. was financed with a Juan de la Cierva contract (FPDI-2013-18167).

Acknowledgments: The authors would like to acknowledge Isaac Janer for his technical support in the experimental field and to Enrico Cretazzo (IFAPA, Malaga, Spain) for his help in some field measurements.

Conflicts of Interest: The authors declare no conflict of interest.

\section{References}

1. FAO. The Future of Food and Agriculture-Trends and Challenges; FAO: Rome, Italy, 2017.

2. Medrano, H.; Tomas, M.; Martorell, S.; Escalona, J.M.; Pou, A.; Fuentes, S.; Flexas, J.; Bota, J. Improving water use efficiency of vineyards in semi-arid regions. A review. Agron. Sustain. Dev. 2015, 35, 499-517. [CrossRef]

3. Lovisolo, C.; Lavoie-Lamoureux, A.; Tramontini, S.; Ferrandino, A. Grapevine adaptations to water stress: New perspectives about soil/plant interactions. Theor. Exp. Plant Phys. 2016, 28, 53-66. [CrossRef]

4. Costa, J.M.; Vaz, M.; Escalona, J.; Egipto, R.; Lopes, C.; Medrano, H.; Chaves, M.M. Modern viticulture in southern Europe: Vulnerabilities and strategies for adaptation to water scarcity. Agric. Water Manag. 2016, 164, 5-18. [CrossRef]

5. Costa, J.M.; Egipto, R.; Silvestre, J.; Lopes, C.; Chaves, M.M. Water and Heat Fluxes in Mediterranean Vineyards: Indicators and Relevance for Management. In Water Scarcity and Sustainable Agriculture in Semiarid Enviroment Tools, Strategies, and Challenges for Woody Crops; Academic Press: Cambridge, MA, USA, 2018; pp. 219-245.

6. Van Leeuwen, C.; Darriet, P. The Impact of Climate Change on Viticulture and Wine Quality. J. Wine Econ. 2016, 11, 150-167. [CrossRef]

7. Vaz, M.; Coelho, R.; Rato, A.; Samara-Lima, R.; Silva, L.L.; Campostrini, E.; Mota, J.B. Adaptive strategies of two Mediterranean grapevines varieties (Aragonez syn. Tempranillo and Trincadeira) face drought: Physiological and structural responses. Theor. Exp. Plant Phys. 2016, 28, 205-220. [CrossRef]

8. Wolkovich, E.M.; de Cortazar-Atauri, I.G.; Morales-Castilla, I.; Nicholas, K.A.; Lacombe, T. From Pinot to Xinomavro in the world's future wine-growing regions. Nat. Clim. Chang. 2018, 8, 29-37. [CrossRef]

9. Morales-Castilla, I.; Garcia de Cortazar-Atauri, I.; Cook, B.I.; Lacombe, T.; Parker, A.; van Leeuwen, C.; Nicholas, K.A.; Wolkovich, E.M. Diversity buffers winegrowing regions from climate change losses. Proc. Natl. Acad. Sci. USA 2020, 117, 2864-2869. [CrossRef]

10. Bota, J.; Tomas, M.; Flexas, J.; Medrano, H.; Escalona, J.M. Differences among grapevine cultivars in their stomatal behavior and water use efficiency under progressive water stress. Agric. Water Manag. 2016, 164, 91-99. [CrossRef]

11. Schultz,H.R. Water relations and photosynthetic responses of two grapevine cultivars of different geographical origin during water stress. Acta Hortic. 1996, 427, 251-266. [CrossRef]

12. Schultz, H.R. Differences in hydraulic architecture account for near-isohydric and anisohydric behaviour of two field-grown Vitis vinifera L. cultivars during drought. Plant Cell Environ. 2003, 26, 1393-1405. [CrossRef]

13. Bota, J.; Flexas, J.; Medrano, H. Genetic variability of photosynthesis and water use in Balearic grapevine cultivars. Ann. Appl. Biol. 2001, 138, 353-361. [CrossRef] 
14. Soar, C.J.; Dry, P.R.; Loveys, B.R. Scion photosynthesis and leaf gas exchange in Vitis vinifera L. cv. Shiraz: Mediation of rootstock effects via xylem sap ABA. Aust. J. Grape Wine Res. 2006, 12, 82-96. [CrossRef]

15. Tomas, M.; Medrano, H.; Pou, A.; Escalona, J.M.; Martorell, S.; Ribas-Carbo, M.; Flexas, J. Water-use efficiency in grapevine cultivars grown under controlled conditions: Effects of water stress at the leaf and whole-plant level. Aust. J. Grape Wine Res. 2012, 18, 164-172. [CrossRef]

16. Tomas, M.; Medrano, H.; Escalona, J.M.; Martorell, S.; Pou, A.; Ribas-Carbo, M.; Flexas, J. Variability of water use efficiency in grapevines. Environ. Exp. Bot. 2014, 103, 148-157. [CrossRef]

17. Costa, J.M.; Ortuno, M.F.; Lopes, C.M.; Chaves, M.M. Grapevine varieties exhibiting differences in stomatal response to water deficit. Funct. Plant Biol. 2012, 39, 179-189. [CrossRef]

18. Pou, A.; Flexas, J.; Alsina, M.D.; Bota, J.; Carambula, C.; de Herralde, F.; Galmes, J.; Lovisolo, C.; Jimenez, M.; Ribas-Carbo, M.; et al. Adjustments of water use efficiency by stomatal regulation during drought and recovery in the drought-adapted Vitis hybrid Richter-110 (V. berlandieri x V. rupestris). Physiol. Plant. 2008, 134, 313-323. [CrossRef] [PubMed]

19. Prieto, J.A.; Lebon, E.; Ojeda, H. Stomatal Behavior of Different Grapevine Cultivars in Response to Soil Water Status and Air Water Vapor Pressure Deficit. J. Int. Sci. Vigne Vin 2010, 44, 9-20. [CrossRef]

20. Chaves, M.M.; Zarrouk, O.; Francisco, R.; Costa, J.M.; Santos, T.; Regalado, A.P.; Rodrigues, M.L.; Lopes, C.M. Grapevine under deficit irrigation: Hints from physiological and molecular data. Ann. Bot. 2010, 105, 661-676. [CrossRef] [PubMed]

21. Medrano, H.; Tortosa, I.; Montes, E.; Pou, A.; Balda, P.; Bota, J.; Escalona, J.M. Genetic improvement of grapevine (Vitis vinifera L.) water use efficiency. In Water Scarcity and Sustainable Agriculture in Semiarid Environment. Tools, Strategies and Challenges for Woody Crops; Academic Press: Cambridge, MA, USA, 2018; pp. 377-401.

22. Pou, A.; Medrano, H.; Tomas, M.; Martorell, S.; Ribas-Carbo, M.; Flexas, J. Anisohydric behaviour in grapevines results in better performance under moderate water stress and recovery than isohydric behaviour. Plant Soil 2012, 359, 335-349. [CrossRef]

23. Klein, $\mathrm{T}$. The variability of stomatal sensitivity to leaf water potential across tree species indicates a continuum between isohydric and anisohydric behaviours. Funct. Ecol. 2014, 28, 1313-1320. [CrossRef]

24. Martinez-Vilalta, J.; Garcia-Forner, N. Water potential regulation, stomatal behaviour and hydraulic transport under drought: Deconstructing the iso/anisohydric concept. Plant Cell Environ. 2017, 40, 962-976. [CrossRef] [PubMed]

25. Hochberg, U.; Rockwell, F.E.; Holbrook, N.M.; Cochard, H. Iso/Anisohydry: A Plant-Environment Interaction Rather Than a Simple Hydraulic Trait. Trends Plant Sci. 2018, 23, 112-120. [CrossRef]

26. Habsburg-Lorena, L.S. Die Eigentlichen Balearen [1871] Die Balearen in Wort und Bild geschildert. In Brockhaus. Traducción castellana (1982-1993): Las Baleares por la palabra y el grabado; Caja de Ahorros de Baleares “Sa Nostra”: Palma de Mallorca, Spain; Leipzig, Germany, 1989.

27. Garcia-Munoz, S.; Lacombe, T.; de Andres, M.T.; Gaforio, L.; Munoz-Organero, G.; Laucou, V.; This, P.; Cabello, F. Grape varieties (Vitis vinifera L.) from the Balearic Islands: Genetic characterization and relationship with Iberian Peninsula and Mediterranean Basin. Genet. Resour. Crop Evol. 2012, 59, 589-605. [CrossRef]

28. Marsal, G.; Bota, J.; Martorell, A.; Canals, J.M.; Zamora, F.; Fort, F. Local cultivars of Vitis vinifera L. in Spanish islands: Balearic Archipelago. Sci. Hortic. 2017, 226, 122-132. [CrossRef]

29. Carvalho, L.C.; Vidigal, P.; Amancio, S. Oxidative stress homeostasis in grapevine (Vitis vinifera L.). Front. Environ. Sci. 2015, 3. [CrossRef]

30. Obata, T.; Fernie, A.R. The use of metabolomics to dissect plant responses to abiotic stresses. Cell. Mol. Life Sci. 2012, 69, 3225-3243. [CrossRef]

31. Peters, K.; Worrich, A.; Weinhold, A.; Alka, O.; Balcke, G.; Birkemeyer, C.; Bruelheide, H.; Calf, O.W.; Dietz, S.; Duhrkop, K.; et al. Current Challenges in Plant Eco-Metabolomics. Int. J. Mol. Sci. 2018, 19, 1385. [CrossRef]

32. Alseekh, S.; Fernie, A.R. Metabolomics 20years on: What have we learned and what hurdles remain? Plant J. 2018, 94, 933-942. [CrossRef]

33. Flexas, J.; Gago, J. A role for ecophysiology in the 'omics' era. Plant J. 2018, 96, 251-259. [CrossRef] 
34. Clemente-Moreno, M.J.; Omranian, N.; Saez, P.; Figueroa, C.M.; Del-Saz, N.; Elso, M.; Poblete, L.; Orf, I.; Cuadros-Inostroza, A.; Cavieres, L.; et al. Cytochrome respiration pathway and sulphur metabolism sustain stress tolerance to low temperature in the Antarctic species Colobanthus quitensis. New Phytol. 2020, 225, 754-768. [CrossRef]

35. Clemente-Moreno, M.J.; Omranian, N.; Saez, P.L.; Figueroa, C.M.; Del-Saz, N.; Elso, M.; Poblete, L.; Orf, I.; Cuadros-Inostroza, A.; Cavieres, L.A.; et al. Low-temperature tolerance of the Antarctic species Deschampsia antarctica: A complex metabolic response associated with nutrient remobilization. Plant Cell Environ. 2020, 43, 1376-1393. [CrossRef] [PubMed]

36. De Ollas, C.; Morillon, R.; Fotopoulos, V.; Puertolas, J.; Ollitrault, P.; Gomez-Cadenas, A.; Arbona, V. Facing Climate Change: Biotechnology of Iconic Mediterranean Woody Crops. Front. Plant Sci. 2019, 10, 427. [CrossRef] [PubMed]

37. Conde, A.; Regalado, A.; Rodrigues, D.; Costa, J.M.; Blumwald, E.; Chaves, M.M.; Geros, H. Polyols in grape berry: Transport and metabolic adjustments as a physiological strategy for water-deficit stress tolerance in grapevine. J. Exp. Bot. 2015, 66, 889-906. [CrossRef]

38. Savoi, S.; Wong, D.C.J.; Arapitsas, P.; Miculan, M.; Bucchetti, B.; Peterlunger, E.; Fait, A.; Mattivi, F.; Castellarin, S.D. Transcriptome and metabolite profiling reveals that prolonged drought modulates the phenylpropanoid and terpenoid pathway in white grapes (Vitis vinifera L.). BMC Plant Biol. 2016, 16, 67. [CrossRef]

39. Hochberg, U.; Batushansky, A.; Degu, A.; Rachmilevitch, S.; Fait, A. Metabolic and Physiological Responses of Shiraz and Cabernet Sauvignon (Vitis vinifera L.) to Near Optimal Temperatures of 25 and 35 degrees C. Int. J. Mol. Sci. 2015, 16, 24276-24294. [CrossRef]

40. Ghan, R.; Van Sluyter, S.C.; Hochberg, U.; Degu, A.; Hopper, D.W.; Tillet, R.L.; Schlauch, K.A.; Haynes, P.A.; Fait, A.; Cramer, G.R. Five omic technologies are concordant in differentiating the biochemical characteristics of the berries of five grapevine (Vitis vinifera L.) cultivars. BMC Genom. 2015, 16, 946. [CrossRef]

41. Pinasseau, L.; Vallverdu-Queralt, A.; Verbaere, A.; Roques, M.; Meudec, E.; Le Cunff, L.; Peros, J.P.; Ageorges, A.; Sommerer, N.; Boulet, J.C.; et al. Cultivar Diversity of Grape Skin Polyphenol Composition and Changes in Response to Drought Investigated by LC-MS Based Metabolomics. Front. Plant Sci. 2017, 8 , 1826. [CrossRef]

42. Degu, A.; Hochberg, U.; Wong, D.C.J.; Alberti, G.; Lazarovitch, N.; Peterlunger, E.; Castellarin, S.D.; Herrera, J.C.; Fait, A. Swift metabolite changes and leaf shedding are milestones in the acclimation process of grapevine under prolonged water stress. BMC Plant Biol. 2019, 19, 69. [CrossRef]

43. Hochberg, U.; Degu, A.; Fait, A.; Rachmilevitch, S. Near isohydric grapevine cultivar displays higher photosynthetic efficiency and photorespiration rates under drought stress as compared with near anisohydric grapevine cultivar. Physiol. Plant. 2013, 147, 443-452. [CrossRef] [PubMed]

44. El Aou-ouad, H.; Bota, J.; Obata, T.; Montero, R.; Fernie, A.R.; Medrano, H.; Pou, A.; Florez-Sarasa, I. Combined drought and virus infection trigger aspects of respiratory metabolism related to grapevine physiological responses. J. Plant Physiol. 2018, 231, 19-30. [CrossRef]

45. Bota, J.; Stasyk, O.; Flexas, J.; Medrano, H. Effect of water stress on partitioning of C-14-labelled photosynthates in Vitis vinifera. Funct. Plant Biol. 2004, 31, 697-708. [CrossRef]

46. Medrano, H.; Escalona, J.M.; Bota, J.; Gulias, J.; Flexas, J. Regulation of photosynthesis of C-3 plants in response to progressive drought: Stomatal conductance as a reference parameter. Ann. Bot. 2002, 89, 895-905. [CrossRef]

47. El Aou-ouad, H.; Pou, A.; Tomas, M.; Montero, R.; Ribas-Carbo, M.; Medrano, H.; Bota, J. Combined effect of virus infection and water stress on water flow and water economy in grapevines. Physiol. Plant. 2017, 160, 171-184. [CrossRef]

48. Groom, P.K.; Lamont, B.B. Which common indices of sclerophylly best reflect differences in leaf structure? Ecoscience 1999, 6, 471-474. [CrossRef]

49. Farquhar, G.D.; Richards, R.A. Isotopic Composition of Plant Carbon Correlates with Water-Use Efficiency of Wheat Genotypes. Aust. J. Plant Physiol. 1984, 11, 539-552. [CrossRef]

50. Lisec, J.; Schauer, N.; Kopka, J.; Willmitzer, L.; Fernie, A.R. Gas chromatography mass spectrometry-based metabolite profiling in plants. Nat. Protoc. 2006, 1, 387-396. [CrossRef] 
51. Luedemann, A.; Strassburg, K.; Erban, A.; Kopka, J. TagFinder for the quantitative analysis of gas chromatography - mass spectrometry (GC-MS)-based metabolite profiling experiments. Bioinformatics 2008, 24, 732-737. [CrossRef]

52. Fernie, A.R.; Aharoni, A.; Willmitzer, L.; Stitt, M.; Tohge, T.; Kopka, J.; Carroll, A.J.; Saito, K.; Fraser, P.D.; DeLuca, V. Recommendations for Reporting Metabolite Data. Plant Cell 2011, 23, 2477-2482. [CrossRef]

53. Howe, E.; Holton, K.; Nair, S.; Schlauch, D.; Sinha, R.; Quackenbush, J. MeV: MultiExperiment Viewer. In Biomedical Informatics for Cancer Research; Springer: Boston, MA, USA, 2010; pp. 267-277. [CrossRef]

54. Florez-Sarasa, I.; Ribas-Carbo, M.; Del-Saz, N.F.; Schwahn, K.; Nikoloski, Z.; Fernie, A.R.; Flexas, J. Unravelling the invivo regulation and metabolic role of the alternative oxidase pathway in C-3 species under photoinhibitory conditions. New Phytol. 2016, 212, 66-79. [CrossRef]

55. Martorell, S.; Diaz-Espejo, A.; Tomas, M.; Pou, A.; El Aou-Ouad, H.; Escalona, J.M.; Vadell, J.; Ribas-Carbo, M.; Flexas, J.; Medrano, H. Differences in water-use-efficiency between two Vitis vinifera cultivars (Grenache and Tempranillo) explained by the combined response of stomata to hydraulic and chemical signals during water stress. Agric. Water Manag. 2015, 156, 1-9. [CrossRef]

56. Flexas, J.; Scoffoni, C.; Gago, J.; Sack, L. Leaf mesophyll conductance and leaf hydraulic conductance: An introduction to their measurement and coordination. J. Exp. Bot. 2013, 64, 3965-3981. [CrossRef]

57. Escalona, J.M.; Flexas, J.; Medrano, H. Stomatal and non-stomatal limitations of photosynthesis under water stress in field-grown grapevines. Aust. J. Plant Physiol. 1999, 26, 421-433. [CrossRef]

58. Poorter, H.; Niinemets, U.; Poorter, L.; Wright, I.J.; Villar, R. Causes and consequences of variation in leaf mass per area (LMA): A meta-analysis. New Phytol. 2009, 182, 565.

59. Rao, R.C.N.; Wright, G.C. Stability of the Relationship between Specific Leaf-Area and Carbon-Isotope Discrimination across Environments in Peanut. Crop Sci. 1994, 34, 98-103. [CrossRef]

60. Hildebrandt, T.M.; Nesi, A.N.; Araujo, W.L.; Braun, H.P. Amino Acid Catabolism in Plants. Mol. Plant 2015, 8, 1563-1579. [CrossRef]

61. Degu, A.; Morcia, C.; Tumino, G.; Hochberg, U.; Toubiana, D.; Mattivi, F.; Schneider, A.; Bosca, P.; Cattivelli, L.; Terzi, V.; et al. Metabolite profiling elucidates communalities and differences in the polyphenol biosynthetic pathways of red and white Muscat genotypes. Plant Physiol. Biochem. 2015, 86, 24-33. [CrossRef]

62. Massonnet, M.; Fasoli, M.; Tornielli, G.B.; Altieri, M.; Sandri, M.; Zuccolotto, P.; Paci, P.; Gardiman, M.; Zenoni, S.; Pezzotti, M. Ripening Transcriptomic Program in Red and White Grapevine Varieties Correlates with Berry Skin Anthocyanin Accumulation. Plant Physiol. 2017, 174, 2376-2396. [CrossRef]

63. Rooy, S.S.B.; Salekdeh, G.H.; Ghabooli, M.; Gholami, M.; Karimi, R. Cold-induced physiological and biochemical responses of three grapevine cultivars differing in cold tolerance. Acta Physiol. Plant. 2017, 39, 264. [CrossRef]

64. Zhang, Y.; Butelli, E.; Alseekh, S.; Tohge, T.; Rallapalli, G.; Luo, J.; Kawar, P.G.; Hill, L.; Santino, A.; Fernie, A.R.; et al. Multi-level engineering facilitates the production of phenylpropanoid compounds in tomato. Nat. Commun. 2015, 6, 8635. [CrossRef]

65. Soubeyrand, E.; Colombie, S.; Beauvoit, B.; Dai, Z.W.; Cluzet, S.; Hilbert, G.; Renaud, C.; Maneta-Peyret, L.; Dieuaide-Noubhani, M.; Merillon, J.M.; et al. Constraint-Based Modeling Highlights Cell Energy, Redox Status and alpha-Ketoglutarate Availability as Metabolic Drivers for Anthocyanin Accumulation in Grape Cells Under Nitrogen Limitation. Front. Plant Sci. 2018, 9, 421. [CrossRef]

66. Maeda, H.; Dudareva, N. The Shikimate Pathway and Aromatic Amino Acid Biosynthesis in Plants. Annu. Rev. Plant Biol. 2012, 63, 73-105. [CrossRef]

67. Clemente-Moreno, M.J.; Gago, J.; Daz-Vivancos, P.; Bernal, A.; Miedes, E.; Bresta, P.; Liakopoulos, G.; Fernie, A.R.; Hernndez, J.A.; Flexas, J. The apoplastic antioxidant system and altered cell wall dynamics influence mesophyll conductance and the rate of photosynthesis. Plant J. 2019, 99, 1031-1046. [CrossRef] [PubMed]

68. Roig-Oliver, M.; Nadal, M.; Clemente-Moreno, M.J.; Bota, J.; Flexas, J. Cell wall components regulate photosynthesis and leaf water relations of Vitis vinifera cv. Grenache acclimated to contrasting environmental conditions. J. Plant Physiol. 2020, 244, 153084. [CrossRef]

69. Flamini, R.; Mattivi, F.; De Rosso, M.; Arapitsas, P.; Bavaresco, L. Advanced Knowledge of Three Important Classes of Grape Phenolics: Anthocyanins, Stilbenes and Flavonols. Int. J. Mol. Sci. 2013, 14, 19651-19669. [CrossRef] 
70. Foyer, C.H.; Noctor, G. Ascorbate and Glutathione: The Heart of the Redox Hub. Plant Physiol. 2011, 155, 2-18. [CrossRef]

71. Ribas-Carbo, M.; Taylor, N.L.; Giles, L.; Busquets, S.; Finnegan, P.M.; Day, D.A.; Lambers, H.; Medrano, H.; Berry, J.A.; Flexas, J. Effects of water stress on respiration in soybean leaves. Plant Physiol. 2005, 139, 466-473. [CrossRef]

72. Del-Saz, N.F.; Florez-Sarasa, I.; Clemente-Moreno, M.J.; Mhadhbi, H.; Flexas, J.; Fernie, A.R.; Ribas-Carbo, M. Salinity tolerance is related to cyanide-resistant alternative respiration in Medicago truncatula under sudden severe stress. Plant Cell Environ. 2016, 39, 2361-2369. [CrossRef]

73. Sanchez-Guerrero, A.; del-Saz, N.F.; Florez-Sarasa, I.; Ribas-Carbo, M.; Fernier, A.R.; Jimenez, A.; Sevilla, F. Coordinated responses of mitochondrial antioxidative enzymes, respiratory pathways and metabolism in Arabidopsis thaliana thioredoxin trxo1 mutants under salinity. Environ. Exp. Bot. 2019, 162, $212-222$. [CrossRef]

(C) 2020 by the authors. Licensee MDPI, Basel, Switzerland. This article is an open access article distributed under the terms and conditions of the Creative Commons Attribution (CC BY) license (http://creativecommons.org/licenses/by/4.0/). 